\title{
Inner-Shell Excitation Spectroscopy and X-ray Photoemission Electron Microscopy of Adhesion Promoters
}

\author{
David Tulumello, Glyn Cooper, Ivo Koprinarov, and Adam P. Hitchcock*,† \\ Department of Chemistry, McMaster University, Hamilton, Ontario L8S 4M1, Canada
}

\author{
Edward G. Rightor, Gary E. Mitchell, Steve Rozeveld, Greg F. Meyers, and Ted M. Stokich \\ The Dow Chemical Company, 1897 Building, Midland, Michigan 48667, and Advanced Electronic Materials, \\ The Dow Chemical Company, 1712 Building, Midland, Michigan 48674
}

Received: January 11, 2005

\begin{abstract}
The C 1s, Si 2p, Si 2s, and O 1s inner-shell excitation spectra of vinyltriethoxysilane, trimethylethoxysilane, and vinyltriacetoxysilane have been recorded by electron energy loss spectroscopy under scattering conditions dominated by electric dipole transitions. The spectra are converted to absolute optical oscillator strength scales and interpreted with the aid of ab initio calculations of the inner-shell excitation spectra of model compounds. Electron energy loss spectra recorded in a transmission electron microscope on partly cured adhesion promoter, atomic force micrographs, and images and X-ray absorption spectra from X-ray photoemission electron microscopy of as-spun and cured vinyltriacetoxysilane-based adhesion promoter films on silicon are presented. The use of these measurements in assisting chemistry studies of adhesion promoters for electronics applications is discussed.
\end{abstract}

\section{Introduction}

Adhesion promoters (APs) are used in various applications including (a) compatibilizing glass fibers with polymer matrixes to increase the strength of composite materials, (b) adhering rear-view mirrors to automotive windshields, (c) enhancing the adhesion of polymers to metal surfaces, (d) modifying the wettability of various surfaces, and (e) controlling the biocompatibility of surfaces. Although these materials have been known at least since the $1940 \mathrm{~s}^{1}$ and have been studied extensively by advanced surface science techniques, ${ }^{2-5}$ there are still many remaining questions about the microscopic structure and modes of action, both in service and in failure. Typical questions include: Does a given adhesion promoter wet a surface of interest? Is there complete or only partial surface coverage? What is the nature of the chemical interactions with the substrate and the adlayer? How do various process parameters affect the quality of the AP film and subsequent adhesion of the adlayer? Our particular interest is adhesion promoters used to enhance the adhesion of thin polymer films for electronic applications such as interlayer dielectrics, multichip modules, and packaging. ${ }^{5}$ The species studied contain both vinyl and acetate groups. Innershell excitation spectroscopic techniques, which can track the presence, loss, and/or chemical transformation of these groups, are of particular value to understand and thus optimize adhesion promoter technologies.

To investigate adhesion promoter layers, both as-spun and after thermal processing, we use a combination of techniques including atomic force microscopy (AFM), electron energy loss (EELS) using transmission electron microscopy (TEM), and near

* Author to whom correspondence should be addressed. Phone: 1-905525-9140 x24749. E-mail: aph@mcmaster.ca

† Present address: Sunnybrook and Women's Health Sciences Centre, University of Toronto, Research Building, Room S656, Toronto, Ontario, M4N 3M5, Canada. edge X-ray absorption spectroscopy (NEXAFS) using X-ray photoemission electron microscopy (X-PEEM). A preliminary report of some of the X-PEEM results has been published. ${ }^{6}$ To assist interpretation of the X-ray absorption and EELS results from the adhesion promoters, we have measured the inner-shell excitation spectra of some of the adhesion promoter compounds in the gas phase. These results, combined with quantum computational studies, provide a fundamental understanding of the spectra and thus allow us to better interpret changes in the inner-shell spectra of the materials in actual applications. This approach, in which the spectral contributions from various bonds and/or functional groups are combined to interpret more complicated spectra, ${ }^{7}$ has been used previously in applications of X-ray absorption spectroscopy and spectromicroscopy to other complex systems such as polyurethanes ${ }^{8-12}$ and biofilms. ${ }^{13}$

In this work, we have used gas-phase inner-shell electron energy loss spectroscopy (ISEELS) to measure the spectra of trimethylethoxysilane (1), vinyltriethoxysilane (2), and vinyltriacetoxysilane (3). Previously, ISEELS studies have been carried out on species containing $\mathrm{Si}-\mathrm{Si}$ bonds, ${ }^{14}$ phenylsubstituted silanol, disilane and disiloxane species, ${ }^{15}$ and unsaturated silylene species. ${ }^{16,17}$ Some of the themes of electronic delocalization that are found to be important in interpreting the vinyl siloxane species examined in this work have counterparts in these earlier studies. The experimental spectra are interpreted by a combination of trends through the series of species and by comparison to ab initio calculations using the GSCF3 method. ${ }^{18,19}$

This paper is organized as follows. After presenting the experimental and computational methods, the results for the gasphase studies are presented and discussed using empirical spectral assignment techniques. This is followed by a detailed presentation of the computational results and further refinement of the spectral assignments through comparison of theory and 
experiment. The third section of the results presents X-PEEM and AFM images from an early test adhesion promoter sample, as-spun and after various degrees of curing. The $\mathrm{C} 1 \mathrm{~s}$ and $\mathrm{O} 1 \mathrm{~s}$ spectra recorded with X-PEEM are compared to spectra recorded with parallel detection electron energy loss (pEELS) via TEM for a cured model adhesion promoter sample. This comparison reveals useful insights into the nature of the species present in the hydrolyzed as-spun coating and its evolution to the chemical composition in its adhesion promotion format. Finally, X-PEEM results from a sample generated with the mature spin-coating process are reported to illustrate the analytical signals of an optimized AP system.

\section{Experimental Section}

2.1. Samples. The samples of trimethylethoxysilane (1), vinyltriethoxysilane (2), and vinyltriacetoxysilane (3) were obtained from Sigma Aldrich, all with a stated purity of greater than $95 \%$. In the case of vinyltriacetoxysilane, the pure compound is clear and odorless, but it is strongly reactive with water vapor. Upon receipt of the compound, it had a pale yellow color and a moderate acetic acid odor. The color and odor increased considerably after exposure to dry air. The vapor of this material was examined. As the sample was consumed, the residual liquid gradually became lighter and eventually transparent, the vapor pressure decreased and eventually stabilized, and the $\mathrm{C} 1 \mathrm{~s}$ spectrum changed from that of acetic acid (the hydrolysis product) to one consistent with the parent compound. The spectra presented herein are after saturation of this sample transformation.

The adhesion promoter films used for the AFM, XPEEM, and TEM experiments were early experimental versions of what has since been developed into commercial AP3000 and AP4000 adhesion promoters intended for use with Dow's advanced electronic resins. The samples for XPEEM and AFM were made from vinyltriacetoxysilane (3), mixing with 15 mol of water per mole of 3 and diluting to 0.3 wt \% 3 with 1-methoxy-2propanol (DOWANOL PM glycol ether). (DOWANOL is a trademark of the Dow Chemical Company). The samples were spin-coated onto silicon wafers at $3000 \mathrm{rpm}$. Films were heated on a hot plate in air for about $90 \mathrm{~s}$ at either 100 or $180 \mathrm{C}^{\circ}$. Final film thicknesses after baking at $180 \mathrm{C}^{\circ}$ were measured to be $2 \mathrm{~nm}$ by ellipsometry. The films for TEM were prepared by dipping a lacey-carbon TEM grid into a solution of $\mathbf{3}$ in propylene glycol methyl ether acetate (DOWANOL PMA glycol ether) at $2.5 \mathrm{wt} \%$, hydrolyzed with $1 \mathrm{~mol}$ of water solution and drying the films in air on a hot plate for $5 \mathrm{~min}$ at $120 \mathrm{C}^{\circ}$.

2.2. ISEELS Measurements. The apparatus and procedures have been described elsewhere. ${ }^{20,21}$ For vinyltriethoxysilane and trimethylethoxysilane, the vapor of the liquid samples introduced into the gas chamber through a variable leak valve was sufficient for good quality spectra. In the case of vinyltriacetoxysilane, after all of the acetic acid had been pumped away, the vapor pressure was too low to obtain good spectra. Thus, the sample ampule was sealed and attached directly to the gas chamber above the leak valve. Gentle heating of the sample ampule was then applied until adequate vapor pressure $\left(1 \times 10^{-6}\right.$ Torr in the main chamber, $\sim 1 \times 10^{-5}$ Torr in the gas cell) was achieved, and a silicon $2 \mathrm{p}$ signal was observed. The shape of the silicon $2 p$ signal remained constant over a range of sample ampule temperatures so we concluded the vapor was mostly vinyltriacetoxysilane, with negligible amounts of acetic acid.

The energy scales were calibrated by acquiring the spectra of a stable mixture of the analyte molecule and a reference compound. The $\mathrm{C} 1 \mathrm{~s}$ and $\mathrm{O} 1 \mathrm{~s}$ spectra were calibrated using

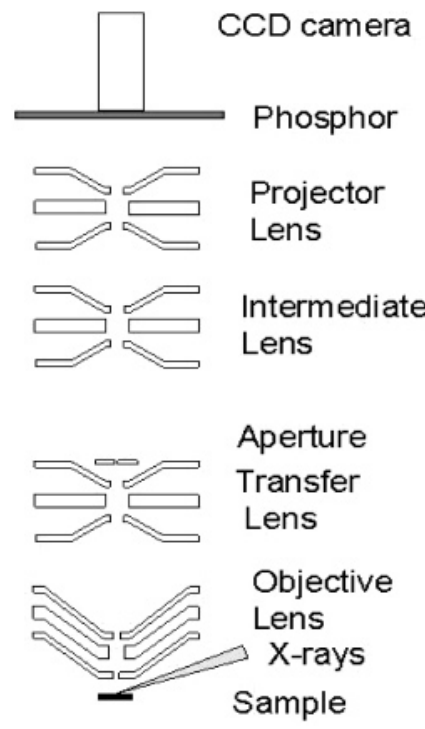

Figure 1. Schematic of the X-ray photoemission electron microscope, PEEM-2, at the Advanced Light Source. ${ }^{26}$ These optics are housed in an ultrahigh vacuum vessel, to which preparation and sample transfer chambers are attached. The instrument is the permanent end station on beamline 7.3.1 at the Advanced Light Source

the $\mathrm{C} 1 \mathrm{~s} \rightarrow \pi^{*}$ transition of $\mathrm{CO}(287.40 \mathrm{eV})^{23}$ and the $\mathrm{O} 1 \mathrm{~s} \rightarrow$ $\pi^{*}$ transition of $\mathrm{CO}(534.20 \mathrm{eV}) .{ }^{24}$ The $\mathrm{Si} 2 \mathrm{p} / 2 \mathrm{~s}$ spectra were calibrated with respect to the $\mathrm{C} 1 \mathrm{~s}$ spectra of each species. The core-excitation spectra associated with a particular core edge are isolated from the underlying valence-shell and core ionization continua by subtracting a smooth curve determined from a curve fit of the function $a(E-\mathrm{b})^{c}$ to the pre-edge experimental signal. The background-subtracted spectra are converted to absolute oscillator strength scales using previously described methods. ${ }^{25}$

2.3. X-PEEM Measurements. Figure 1 is a schematic of the electrostatic X-PEEM instrument ${ }^{26}$ at beamline 7.3.1 at the Advanced Light Source (ALS) used to record images and X-ray absorption spectra from the adhesion promoter samples. Full details of the instrument and operating procedures have been presented elsewhere. ${ }^{26,27}$ Briefly, the sample is illuminated obliquely $\left(30^{\circ}\right.$ incidence $)$ by a spot of X-rays that is approximately $30 \mu \mathrm{m}(H) \times 50 \mu \mathrm{m}(V)$ as seen by the PEEM. Primary and secondary electrons ejected from the near surface region (total sampling depth is $\sim 5-10 \mathrm{~nm}$ ) are collected with high efficiency by the strong objective field $(9 \mathrm{kV} / \mathrm{mm})$ and passed through a series of electrostatic lenses that form a magnified image on a phosphor screen. These images are recorded with a charge coupled device (CCD) camera. There is no intentional analysis of the kinetic energy distribution of the electrons, but the lens properties are such that the efficiency is much greater for low-energy secondary electrons $(<10 \mathrm{eV})$, and thus the signal is rather similar to that acquired in partial yield NEXAFS. ${ }^{7} \mathrm{X}$-ray absorption spectra are obtained by measuring images over a sequence of photon energies covering the innershell edge of interest. If the full images are saved ("stacks" 28 ), then one has a spectrum at each pixel that can be analyzed at a later time. Otherwise, the user selects a region of interest, and only the average signal from that region is saved ("spectral" mode).

$\mathrm{X}$-PEEM of organic materials is challenging because of potential problems with charging, field emission, and radiation damage. In this case, the AP layers were sufficiently thin that charging was not an issue. Although the measurements were made relatively early in the evolution of our experimental capabilities, we have reasonable confidence that the doses used 
were low enough that radiation damage is not a factor in our interpretation. We note that, although we have used both $\mathrm{C} 1 \mathrm{~s}$ and $\mathrm{O} 1$ s edge measurements, the $\mathrm{C} 1$ s signal around $285 \mathrm{eV}$ is the most useful and this is recorded early in the measurements, where there has been relatively little dose.

Measurements were made using the full flux with a total exposure time of several minutes. Under the conditions used, the bending magnet beam is elliptically polarized with 70$80 \%$ right circularly polarized light. The electrostatic field at the sample was typically $9 \mathrm{kV} / \mathrm{mm}$. The intermediate voltage was selected so that the field-of-view was about $60 \mu \mathrm{m}$. The energy scales were calibrated from the dip in the incident flux in the $\mathrm{C} 1 \mathrm{~s}$ region. The incident flux (Io), measured from HFetched $\mathrm{Si}$, was corrected for the elemental photoabsorption response of $\mathrm{Si}^{29}$ Image sequences (stacks) ${ }^{28}$ were recorded and prepared for analysis by energy calibration and normalization to the elemental-corrected Io. The aXis2000 X-ray microscopy analysis package ${ }^{30}$ was used to process the X-PEEM data.

2.4. AFM Imaging. Atomic force microscopy (AFM) images were recorded with a Nanoscope III using a Dimension 3000 large-sample AFM and "G" scanner head (Veeco, Inc.). The system is also equipped with a phase extender module. The microscope was operated in the tapping mode, where the lever is oscillated at resonance and the feedback control adjusts for constant tapping amplitude. Scanning was carried out in air using commercially available silicon $125 \mu \mathrm{m}$ cantilevers and tips with nominal force constants of $48 \mathrm{~N} / \mathrm{m}$. Estimated normal scanning forces under these conditions are in the $10^{-8}-10^{-9} \mathrm{~N}$ range. Digital images were recorded at $512 \times 512$ pixels. Perspective gray scale images have been used to enhance the features of interest. Height measurements were made using the statistical programs supplied by the manufacturer (version 4.23r3).

2.5. Electron Energy Loss Spectroscopy in a Transmission Electron Microscope. Electron energy loss spectra (pEELS) were recorded using a JEOL 2010F field-emission TEM located at the Dow Chemical Analytical Laboratories in Midland, MI. The accelerating voltage was $200 \mathrm{keV}$, and the probe current was $0.36 \mathrm{nA}$. The JEOL $2010 \mathrm{~F}$ at Dow is equipped with a Gatan ENFINA 776 spectrometer with a resolution full width at halfmaximum (fwhm) of $1.2 \mathrm{eV} /$ channel at $200 \mathrm{kV}$. The dispersion was set to $0.1 \mathrm{eV} /$ channel. Each spectrum is the sum of 100 individual spectra using acquisition times of 2 s/spectra (for silicon L edge), 4 s/spectra (for carbon K edge), and 6 s/spectra (for oxygen K edge). Spectra were acquired using a defocused probe with a diameter of $\sim 50 \mathrm{~nm}$ in the diffraction mode setting using a camera length of $8 \mathrm{~cm}$ with a collection semiangle of $7.0 \mathrm{mrad}$ and a convergence semiangle of $6.3 \mathrm{mrad}$. The energy loss scales for the Si $2 \mathrm{p}$ and $\mathrm{C}$ 1s pEEL spectra were in good agreement with those from X-ray absorption and ISEELS (for equivalent features), but the $\mathrm{O} 1 \mathrm{~s}$ pEEL spectrum required a $5.3 \mathrm{eV}$ shift to higher energy to match the X-ray absorption results.

2.6. Computational Methods. To gain insight into the relationship of the molecular electronic structure and the innershell spectra, calculations were performed using Gaussian selfconsistent field, version 3, (GSCF3), ${ }^{18,19}$ which is an ab initio code designed specifically for inner-shell excitation and ionization calculations. The program uses the Hartree-Fock-SCF approach to solve for the energies and molecular orbitals of the system under investigation. The basis sets used are those of Huzinaga et al. ${ }^{31}$ The improved virtual orbital (IVO) method, ${ }^{18,32}$ which explicitly takes into account the core hole in the HartreeFock approximation, is used to perform quantum calculations on core-excited molecules. In this approach, the core electron
TABLE 1: Geometries and Basis Sets for Core-Excitation GSCF3 Computations of Trimethylethoxysilane (1), Vinyltrithoxysilane (2), Vinyltriacetoxysilane (3), and Vinylsilane (4) $)^{a, b}$

\begin{tabular}{|c|c|c|c|c|c|c|c|}
\hline & \multicolumn{3}{|c|}{ coordinates $(\AA)$} & & \multicolumn{3}{|c|}{ coordinates $(\AA)$} \\
\hline & $x$ & $y$ & $z$ & & $x$ & $y$ & $z$ \\
\hline \multicolumn{4}{|c|}{ Trimethylethoxysilane (1) } & \multicolumn{4}{|c|}{ Vinyltriacetoxysilane (3) } \\
\hline $\mathrm{Si}$ & -0.297 & 0.000 & 0.079 & $\mathrm{Si}$ & 0.076 & -0.050 & -0.390 \\
\hline $\mathrm{O}$ & -1.943 & 0.000 & 0.303 & $\mathrm{O}$ & 1.036 & -1.228 & -0.994 \\
\hline $\mathrm{C}$ & 0.230 & 1.538 & -0.878 & $\mathrm{O}$ & -1.061 & -0.684 & 0.643 \\
\hline $\mathrm{C}$ & 0.230 & -1.538 & -0.878 & $\mathrm{O}$ & 2.693 & -2.672 & -1.156 \\
\hline $\mathrm{C}$ & 0.443 & 0.000 & 1.805 & $\mathrm{O}$ & 0.287 & -1.520 & 2.193 \\
\hline $\mathrm{H}$ & -0.067 & 2.446 & -0.359 & $\mathrm{O}$ & -0.255 & 2.114 & 1.702 \\
\hline $\mathrm{H}$ & 0.127 & 0.876 & 2.364 & 0 & 1.139 & 0.928 & 0.440 \\
\hline $\mathrm{H}$ & 1.309 & -1.572 & -1.007 & $\mathrm{C}$ & -2.119 & 1.021 & -1.735 \\
\hline $\mathrm{H}$ & -2.504 & 0.000 & -0.458 & $\mathrm{C}$ & -0.814 & 0.793 & -1.753 \\
\hline $\mathrm{H}$ & -0.213 & 1.570 & -1.872 & $\mathrm{C}$ & 2.129 & -1.854 & -0.530 \\
\hline $\mathrm{H}$ & 1.309 & 1.572 & -1.007 & $\mathrm{C}$ & -0.802 & -1.291 & 1.792 \\
\hline $\mathrm{H}$ & -0.213 & -1.570 & -1.872 & $\mathrm{C}$ & 0.840 & 1.848 & 1.350 \\
\hline \multirow[t]{6}{*}{ 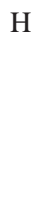 } & -0.067 & -2.446 & -0.359 & $\mathrm{H}$ & -2.742 & 0.724 & -0.910 \\
\hline & & & & $\mathrm{H}$ & -2.619 & 1.518 & -2.549 \\
\hline & & & & $\mathrm{H}$ & -0.241 & 1.113 & -2.609 \\
\hline & & & & $\mathrm{H}$ & 2.429 & -1.531 & 0.459 \\
\hline & & & & $\mathrm{H}$ & -1.711 & -1.556 & 2.316 \\
\hline & & & & $\mathrm{H}$ & 1.734 & 2.326 & 1.731 \\
\hline \multicolumn{4}{|c|}{ Vinyltrihydroxysliane (2) } & \multicolumn{4}{|c|}{ Vinylsilane (4) } \\
\hline $\mathrm{Si}$ & 0.577 & -0.126 & 0.407 & $\mathrm{Si}$ & 0.883 & -0.254 & 0.913 \\
\hline $\mathrm{O}$ & 1.413 & 1.170 & 0.980 & $\mathrm{C}$ & -0.358 & 0.607 & -0.194 \\
\hline $\mathrm{O}$ & 1.748 & -1.223 & 0.085 & $\mathrm{C}$ & -1.024 & -0.003 & -1.163 \\
\hline $\mathrm{O}$ & -0.457 & -0.747 & 1.512 & $\mathrm{H}$ & 0.479 & -0.160 & 2.332 \\
\hline C & -1.744 & 0.089 & -1.165 & $\mathrm{H}$ & 0.971 & -1.678 & 0.529 \\
\hline $\mathrm{C}$ & -0.446 & 0.338 & -1.066 & $\mathrm{H}$ & 2.220 & 0.363 & 0.788 \\
\hline $\mathrm{H}$ & -0.093 & -1.326 & 2.167 & $\mathrm{H}$ & -0.547 & 1.659 & -0.038 \\
\hline $\mathrm{H}$ & 2.641 & -0.912 & 0.131 & $\mathrm{H}$ & -1.733 & 0.515 & -1.787 \\
\hline $\mathrm{H}$ & 0.923 & 1.933 & 1.252 & $\mathrm{H}$ & -0.892 & -1.050 & -1.380 \\
\hline $\mathrm{H}$ & 0.040 & 0.844 & -1.888 & & & & \\
\hline $\mathrm{H}$ & -2.285 & -0.412 & -0.383 & & & & \\
\hline $\mathrm{H}$ & -2.319 & 0.373 & -2.031 & & & & \\
\hline
\end{tabular}

${ }^{a}$ These geometries were obtained from Hartree-Fock geometry optimization calculations performed at the $6-31 \mathrm{G}^{*}$ level. ${ }^{b}$ Basis sets (Huzinaga contracted Gaussian type orbitals ${ }^{30}$ ): HTS3X for Si (contracted 31121111 311111); PRM6G xxx 2* d-polarization $(\mathrm{xxx}=$ element specific) on Si and core hole; HTS8X for C and O (contracted 411121 21111); HTS3Xfor H (6).

is removed directly from an inner-shell orbital specified by the user. The virtual orbitals of this system provide a good approximation to the term values of the core-excitation features at that site. A separate calculation is performed for each distinct chemical site in each molecule. Table 1 lists the geometries and the basis sets used in the GSCF3 theoretical calculations. The detailed methodology of the calculations has been described elsewhere. ${ }^{33}$ The absolute accuracy of the computed coreexcitation energies depends on the size of the basis set used. For the molecules examined in the present study, a number of basis sets were explored, and the final set selected was chosen to give an improved match to the $\mathrm{Si} 2 \mathrm{p}$ spectra. Lower quality basis sets did not reproduce the lower-energy features in the $\mathrm{Si}$ $2 p$ spectra at all. It was also found necessary to choose a very split contraction scheme for the $\mathrm{Si}, \mathrm{C}$, and $\mathrm{O}$ atomic valence levels to produce satisfactory results. The core state term values $(\mathrm{TV}=\mathrm{IP}-E$, where IP is the ionization potential) are more accurate and relatively independent of basis set choices. The core-excitation term values and optical oscillator strengths generated by the GSCF3 calculations are used to generate simulated core-excitation spectra by summing Gaussian lines at an energy given by the term value, an area given by the oscillator strength for excitation to each improved virtual orbital, and a width chosen as a function of the term value (for details 


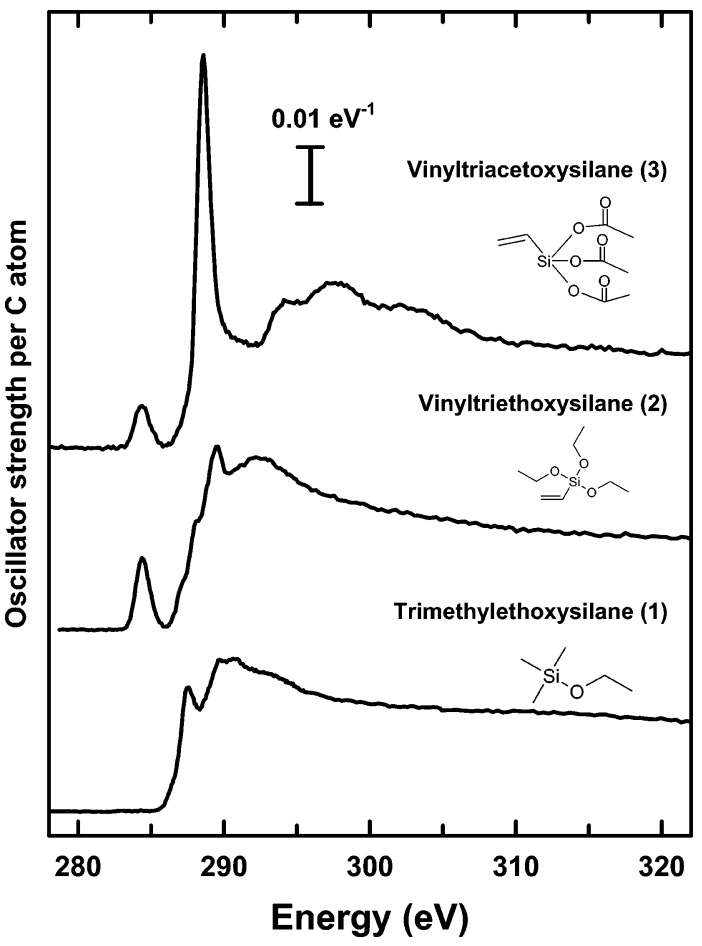

Figure 2. Carbon 1s oscillator strength spectra of trimethylethoxysilane (1), vinyltriethoxysilane (2), and vinyltriacetoxysilane (3) derived from inner-shell electron energy loss spectra recorded with $2.5 \mathrm{keV}$ final electron energy and $\sim 2^{\circ}$ scattering angle. Energies and tentative assignments for the features are listed in Table 2. Offsets are used for clarity.

see the footnotes to the table summarizing the computational results). In comparison of the computed and experimental spectra, the calculated transition energies are retained, but a rigid shift of the computed energy scale relative to the experimental energy scale is built into the plot presentation. These shifts, which range from 0.0 to $3.5 \mathrm{eV}$, are indicated in the figure captions. They are typical of the inaccuracies found in other applications of GSCF3 to core excitation. ${ }^{33}$

\section{Results}

3.1. Carbon 1s Spectra. Figure 2 presents the carbon $1 \mathrm{~s}$ spectra for the three compounds, on an oscillator strength per carbon atom scale, derived from the ISEELS data. Table 2 lists the energies and proposed assignments for the $\mathrm{C} 1 \mathrm{~s}$ spectral features of each species. There are several key differences in the spectra of the three compounds investigated. The peak at $284.4 \mathrm{eV}$ in the spectra of vinyltriethoxysilane and vinyltriacetoxysilane is characteristic of the vinyl group present in these compounds. These peaks are caused by the $\mathrm{C} 1 \mathrm{~s}(\mathrm{C}=\mathrm{C}) \rightarrow$ $\pi^{*}{ }_{\mathrm{C}=\mathrm{C}}$ transition of the vinyl group. In comparison to other alkene systems, the transition energy is remarkably low, indicating appreciable charge transfer from the $\mathrm{Si}-\mathrm{O}$ groups to the vinyl groups. Another characteristic feature of the vinyltriacetoxysilane spectrum is the strong peak at $288.6 \mathrm{eV}$. This peak, which is characteristic of the carboxyl group, is due to $\mathrm{C} 1 \mathrm{~s}(\mathrm{C}=\mathrm{O}) \rightarrow \pi^{*}{ }_{\mathrm{C}=\mathrm{O}}$ transitions. The feature is absent in the spectra of the other two compounds. The two high-energy features of vinyltriacetoxysilane $(298,303 \mathrm{eV})$ are characteristic of the ester group, corresponding to the $\mathrm{C} 1 \mathrm{~s}(\mathrm{C}-\mathrm{O}) \rightarrow \sigma^{*}{ }_{\mathrm{C}-\mathrm{O}}$ and $\mathrm{C} 1 \mathrm{~s}(\mathrm{C}=\mathrm{O}) \rightarrow \sigma^{*} \mathrm{C}=\mathrm{O}$ transitions. The other low-energy features in trimethylethoxysilane and vinyltriethoxysilane arise from the overlap of many different transitions into antibonding orbitals of $\mathrm{C}-\mathrm{Si}, \mathrm{C}-\mathrm{O}$, and $\mathrm{C}-\mathrm{H}$ character, also with partial
TABLE 2: Energies (eV) and Proposed Assignments for Carbon 1s Spectral Features of Trimethylethoxysilane (1), Vinyltriethoxysilane (2), and Vinyltriacetoxysilane (3)

\begin{tabular}{|c|c|c|c|c|c|}
\hline \multicolumn{3}{|c|}{ energy $( \pm 0.1 \mathrm{eV})$} & \multicolumn{3}{|c|}{ assignment (final orbital) } \\
\hline 1 & 2 & 3 & $\mathrm{C}=\mathrm{C}$ & $\mathrm{C}=\mathrm{O}$ & $\mathrm{CH}_{n}$ \\
\hline 28750 & $284.4^{b}$ & $284.4^{c}$ & $\pi^{*} \mathrm{C}=\mathrm{C}$ & & Pn Dudbar \\
\hline & 287.3 & 286.9 & $\begin{array}{l}3 \mathrm{~s} / \sigma^{*} \mathrm{C}-\mathrm{Si} \\
\pi^{*} \mathrm{C}=\mathrm{O}\end{array}$ & & उр кушетв \\
\hline 289.7 & 288.2 & 2886 & $\sigma^{*} \mathrm{C}-\mathrm{Si}$ & $\pi^{*}$ & $\sigma^{*} \mathrm{C}-\mathrm{Si}$ \\
\hline 290.7 & 289.5 & 291.3 & $\begin{array}{l}\sigma^{*} \mathrm{C}-\mathrm{H} \\
\sigma^{*}{ }_{\mathrm{C}-\mathrm{H}}\end{array}$ & & $\sigma^{*} \mathrm{C}-\mathrm{Si}$ \\
\hline 293.3 & 292.5 & $\begin{array}{l}294.1 \\
298 \\
303\end{array}$ & $\sigma^{*}{ }_{\mathrm{C}-\mathrm{Si}}$ & $\begin{array}{l}\sigma^{*} \mathrm{C}-\mathrm{O} \\
\sigma^{*} \mathrm{C}=\mathrm{O}\end{array}$ & $\sigma^{*}{ }_{\mathrm{C}-\mathrm{Si}}$ \\
\hline
\end{tabular}

${ }^{a}$ Calibration: $+0.10(10) \mathrm{eV}$ relative to $\mathrm{CO} \mathrm{C} 1 \mathrm{~s} \rightarrow \pi^{*}\left(287.40^{23}\right)$. ${ }^{b}$ Calibration: $-3.01(7) \mathrm{eV}$ relative to $\mathrm{CO} \mathrm{C} 1 \mathrm{~s} \rightarrow \pi^{*} .{ }^{c}$ Calibration: $-3.03(6) \mathrm{eV}$ relative to $\mathrm{CO} \mathrm{C} 1 \mathrm{~s} \rightarrow \pi^{*}$.

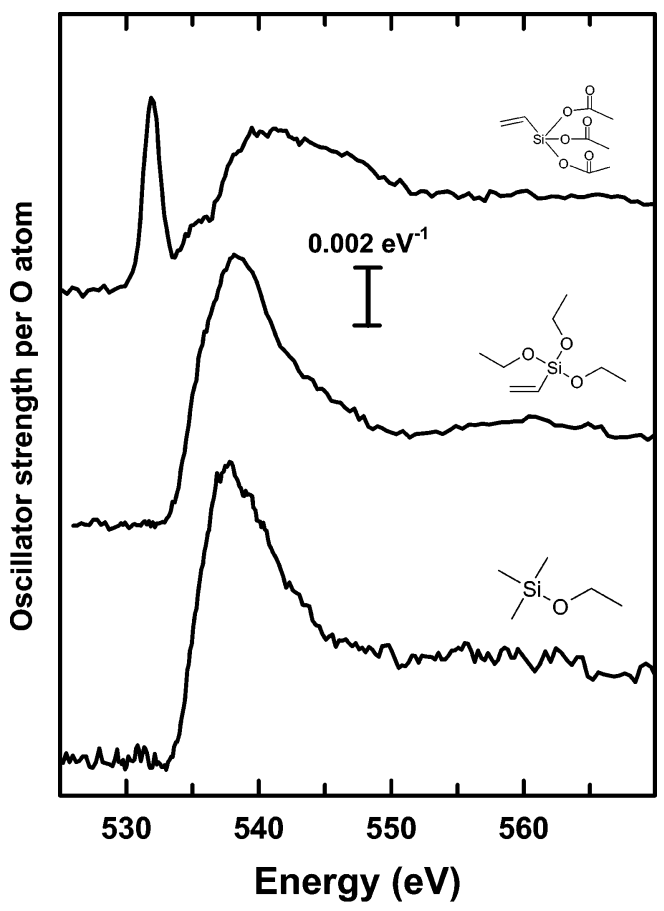

Figure 3. Oxygen 1s oscillator strength spectra of trimethylethoxysilane (1), vinyltriethoxysilane (2), and vinyltriacetoxysilane (3) derived from inner-shell electron energy loss spectra recorded with $2.5 \mathrm{keV}$ final electron energy and $\sim 2^{\circ}$ scattering angle. Energies and tentative assignments for the features are listed in Table 3. Offsets are used for clarity.

Rydberg character. These features cannot be used easily for qualitative analysis. A more detailed discussion and assignment of the $\mathrm{C} 1 \mathrm{~s}$ spectra is presented in section 3.4 below, in comparison to the computational results.

3.2. Oxygen 1s Spectra. Figure 3 presents the $O 1$ s spectra for the three compounds on an oscillator strength per oxygen atom scale, derived from the ISEELS data. Table 3 lists the energies and proposed assignments for the $\mathrm{O} 1 \mathrm{~s}$ spectral features of each species. The $\mathrm{O} 1 \mathrm{~s}$ spectra for all three molecules each contain strong features at 538 and $560 \mathrm{eV}$, representing transitions to similar $\sigma^{*}$ orbitals in each molecule. Although the oxygen $1 \mathrm{~s}$ spectra of vinyltriethoxysilane and trimethylethoxysilane only contain these two features, there are two additional features in the spectrum of vinyltriacetoxysilane that 
TABLE 3: Energies and Proposed Assignments for Oxygen 1s Spectral Features of Trimethylethoxysilane (1), Vinyltriethoxysilane (2), and Vinyltriacetoxysilane (3)

\begin{tabular}{|c|c|c|c|c|c|}
\hline \multicolumn{3}{|c|}{ energy $( \pm 0.1 \mathrm{eV})$} & \multicolumn{3}{|c|}{ assignment (final orbital) } \\
\hline 1 & 2 & 3 & all & $\mathrm{O}=\mathrm{C}-\mathrm{O}(\mathbf{3})$ & $\mathrm{O}-\mathrm{C}=\mathrm{O}(\mathbf{3})$ \\
\hline $537.4^{a}$ & $538.4^{b}$ & $\begin{array}{l}531.9^{c} \\
535.3 \\
539.5\end{array}$ & $\sigma^{*}{ }_{\mathrm{S}-\mathrm{O}}, \sigma^{*}{ }_{\mathrm{C}-\mathrm{O}}$ & $\begin{array}{l}\pi^{*} \mathrm{C}=\mathrm{O} \\
\sigma^{*} \mathrm{C}-0\end{array}$ & $\pi^{*} \mathrm{C}=\mathrm{O}$ \\
\hline 559.1 & 560.9 & $\begin{array}{l}547(\mathrm{sh}) \\
559.6\end{array}$ & $\sigma^{*}$ & & $\sigma^{*} \mathrm{C}=\mathrm{O}$ \\
\hline
\end{tabular}

${ }^{a}$ Calibration: $+3.2(2) \mathrm{eV}$ relative to $\mathrm{CO} \mathrm{O} 1 \mathrm{~s} \rightarrow \pi^{*}\left(534.2^{23}\right)$. ${ }^{b}$ Calibration: $+4.2(2) \mathrm{eV}$ relative to $\mathrm{CO} \mathrm{O} 1 \mathrm{~s} \rightarrow \pi^{*} .{ }^{c}$ Calibration: $-2.3(2) \mathrm{eV}$ relative to $\mathrm{CO} \mathrm{O} 1 \mathrm{~s} \rightarrow \pi^{*}$.

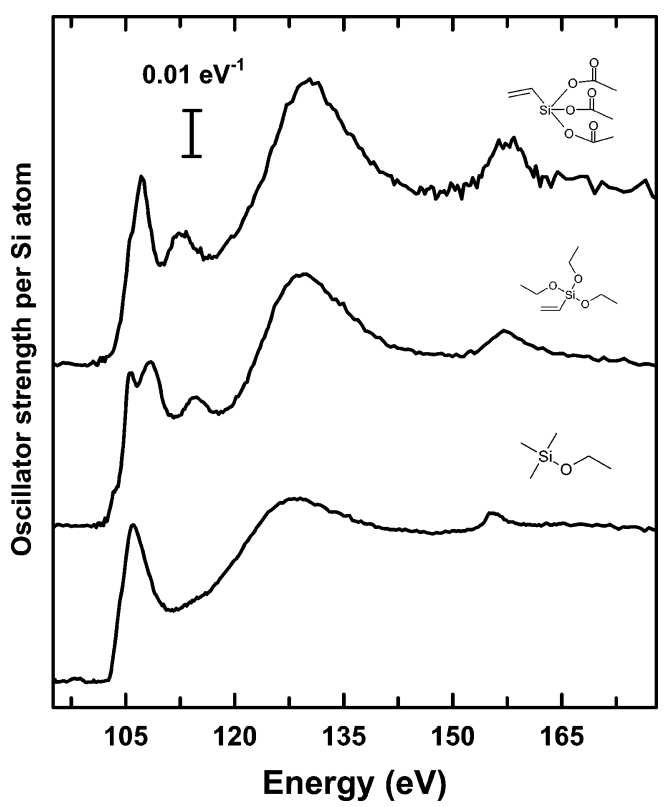

Figure 4. Silicon $2 \mathrm{p}$ and $\mathrm{Si} 2 \mathrm{~s}$ oscillator strength spectra of trimethylethoxysilane (1), vinyltriethoxysilane (2), and vinyltriacetoxysilane (3) derived from inner-shell electron energy loss spectra recorded with $2.5 \mathrm{keV}$ final electron energy and $\sim 2^{\circ}$ scattering angle. Energies and tentative assignments for the features are listed in Table 4. Offsets are used for clarity.

are unique to it alone. These features, due to the carbonyl group, consist of the $\mathrm{O} 1 \mathrm{~s}(\mathrm{C}=\mathrm{O}) \rightarrow \pi^{*}{ }_{\mathrm{C}=\mathrm{O}}$ transition at $532.0 \mathrm{eV}$ and the $\mathrm{O} 1 \mathrm{~s}(\mathrm{C}-\mathrm{O}) \rightarrow \pi^{*}{ }_{\mathrm{C}=\mathrm{O}}$ transition at $535.4 \mathrm{eV}$. The latter transitions have been identified earlier in the $\mathrm{O} 1 \mathrm{~s}$ spectra of other ester molecules. ${ }^{34,35}$ The significant broadening on the high-energy side of the $538 \mathrm{eV}$ peak in vinyltriacetoxysilane is associated with $\mathrm{O} 1 \mathrm{~s}(\mathrm{C}=\mathrm{O}) \rightarrow \sigma^{*} \mathrm{C}=\mathrm{O}$ transitions around 547 $\mathrm{eV}$, also observed in the spectra of other esters.

3.3. Silicon $2 p / 2 s$ Spectra. Figure 4 presents the $S i 2 p / 2 s$ spectra for the three compounds, on an oscillator strength per silicon atom scale, derived from the ISEELS data. Table 4 gives the energies and proposed assignments for the $\mathrm{Si} 2 \mathrm{p} / 2 \mathrm{~s}$ spectral features of each species. The spectra of all three compounds have similar features around 105, 107, 130, and $157 \mathrm{eV}$. The features at 107 and $130 \mathrm{eV}$ are assigned to $\mathrm{Si} 2 \mathrm{p}$ excitations to continuum resonances with partial $3 \mathrm{~d}$ character. According to the computations, there are also excitations to $\sigma^{*}$ orbitals with $\mathrm{Si}-\mathrm{C}$ and $\mathrm{Si}-\mathrm{O}$ character in this region. Relatively intense $\mathrm{Si}$ $2 \mathrm{p}$ continuum resonances are found in the spectra of many other Si species. They are probably related to angular momentum barriers associated with $\mathrm{p} \rightarrow \mathrm{d}$ transitions. ${ }^{7}$ The highest-energy peak at $157 \mathrm{eV}$ is due to $\mathrm{Si} 2 \mathrm{~s} \rightarrow \sigma^{*} \mathrm{Si}-\mathrm{C}$ transitions.

Besides these similarities, there is a notable difference between the Si $2 \mathrm{p}$ spectrum of trimethylethoxysilane and the
TABLE 4: Energies and Proposed Assignments for Silicon 2p and 2s Spectral Features of Trimethylethoxysilane (1), Vinyltriethoxysilane (2), and Vinyltriacetoxysilane (3)

\begin{tabular}{|c|c|c|c|}
\hline \multicolumn{3}{|c|}{ energy $( \pm 0.1 \mathrm{eV})$} & \multirow{2}{*}{$\frac{\text { assignment (final orbital) }}{\text { Si } 2 \mathrm{p}}$} \\
\hline 1 & 2 & 3 & \\
\hline & 103.6 & 103.9 & $\pi^{*}{ }_{\mathrm{C}=\mathrm{C}}\left(\pi_{\mathrm{Si}-\mathrm{C}}\right)$ \\
\hline 104.3 & $105.6^{b}$ & 105.6 & $\sigma_{\mathrm{Si}-\mathrm{C}} / \sigma^{*} \mathrm{Si-O}$ \\
\hline $105.9^{a}$ & 108.4 & $107.2^{c}$ & $\sigma^{*}{ }_{\mathrm{Si}-\mathrm{C}} / \sigma^{*} \mathrm{Si}-\mathrm{O}$ \\
\hline & 114.6 & 112.5 & $\sigma^{*} / \pi^{*} \mathrm{Si}-\mathrm{C}, \mathrm{Si}-\mathrm{O}$, \\
\hline 128.4 & 129.2 & 130.4 & $\sigma^{*}$ \\
\hline 155.5 & 157.1 & 157.5 & $(\mathrm{Si} 2 \mathrm{~s}) \rightarrow \sigma^{*}$ \\
\hline
\end{tabular}

${ }^{a}$ Calibration: $-181.6(1) \mathrm{eV}$ relative to $\mathrm{C} 1 \mathrm{~s} \rightarrow 3 \mathrm{p}$ (feature 2 of compound 1 in Table 2). ${ }^{b}$ Calibration: $-178.8(1) \mathrm{eV}$ relative to $\mathrm{C} 1 \mathrm{~s}$ $\rightarrow \pi^{*}$ (feature 1 of compound 2 in Table 2). ${ }^{c}$ Calibration: $-177.2(1)$ $\mathrm{eV}$ relative to $\mathrm{C} 1 \mathrm{~s} \rightarrow \pi^{*}$ (feature 1 of compound 3 in Table 2).

Si $2 p$ spectra of vinyltriethoxysilane and vinyltriacetoxysilane. The Si 2 p spectra of the latter two compounds, each of which contains a vinyl group bonded to the central silicon atom, exhibit a low-energy shoulder around $104 \mathrm{eV}$ and an additional peak around $113 \mathrm{eV}$. Both of these features are attributed to the presence of the vinyl group, which interacts with the Si orbitals, leading to significant intensity from Si $2 p \rightarrow \pi^{*}{ }_{C}=C$ transitions

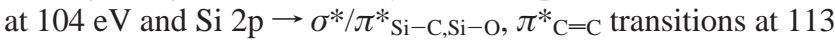
$\mathrm{eV}$.

\section{Comparison to GSCF3 Calculations}

$\mathrm{Ab}$ initio calculations were performed to understand the nature of the optical orbitals involved in the observed transitions. These calculations for the three model compounds are shown in Figures 5-7. Plots of the molecular orbital diagrams for the upper level in selected core-excited states are provided in Figure 8. GSCF3 calculations were performed on the model compounds trimethylhydroxysilane, vinylsilane, vinyltrihydroxysilane, and vinyltriformoxysilane for comparison to the experimental spectra of trimethylethoxysilane, vinyltriethoxysilane, and vinyltriacetoxysilane, respectively. These models were used to reduce the size of the theoretical calculations. Due to the use of model species, the computed spectra will show some differences from the experimental results simply because certain atoms in the actual molecules are not present in the model structures and because there are some bonds in the model species that are not present in the actual species. However, the model compounds are close in structure to the experimentally studied species, differing only in that aliphatic hydrocarbon groups were replaced with $\mathrm{H}$ atoms. Thus, we expect spectral differences to be minimal, except for vinylsilane, which was calculated specifically to attempt to isolate features attributable to the vinyl grouping and for features associated with the $\mathrm{O}-\mathrm{H}$ group.

4.1. Trimethylhydroxysilane. Figure 5 plots the $\mathrm{Si} 2 \mathrm{p}, \mathrm{C}$ 1s, and $\mathrm{O} 1 \mathrm{~s}$ spectra computed by GSCF3 for trimethylhydroxysilane. The experimental spectra of trimethylethoxysilane are included for comparison. Note that the energies and intensities in Figure 5 are on absolute scales for both the computed and experimental results and reflect the full oscillator strength for the indicated molecules (as opposed to the per atom oscillator strength presentations used in Figures 2-4). Offsets are used for clarity. Table 5 summarizes the calculated transition energies, oscillator strengths, and orbital characters of selected lowenergy, inner-shell excited states of trimethylhydroxysilane. The shape of the Si $2 p$ experimental spectrum of trimethylethoxysilane is reproduced reasonably well by the theoretical calculations. In particular, the shape of the band centered at $\sim 106.5$ $\mathrm{eV}$ is simulated accurately. It is revealed by the calculations to be composed of Si $2 \mathrm{p}$ excitations to orbitals of $\sigma^{*} \mathrm{Si-C}$ (but $\pi_{\mathrm{Si}-\mathrm{O}}$ 


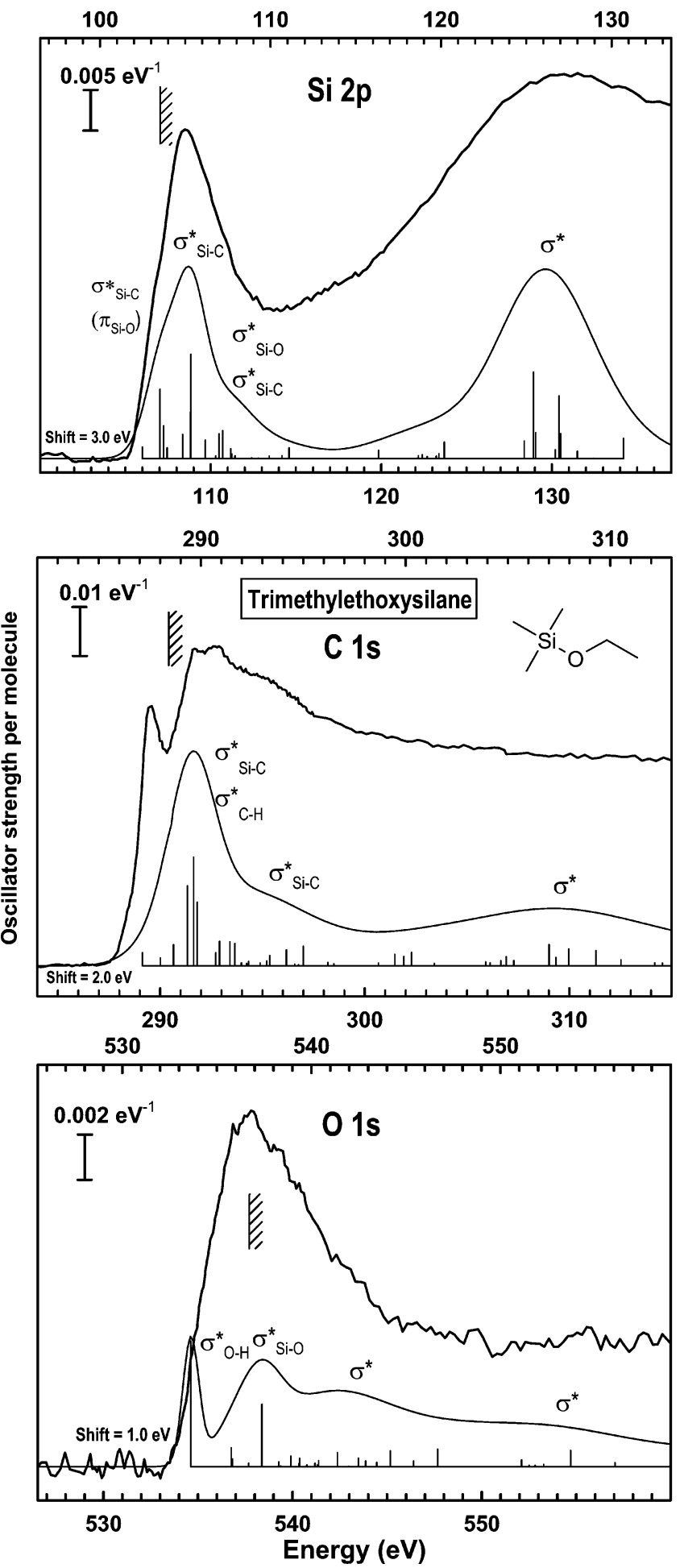

Figure 5. Simulated $\mathrm{Si} 2 \mathrm{p}, \mathrm{C} 1 \mathrm{~s}$, and $\mathrm{O} 1 \mathrm{~s}$ spectra of trimethylhydroxysilane computed by GSCF3 ab initio methods, compared to the corresponding experimental spectra of trimethylethoxysilane. Shifts of 3.0, 2.0, and $1.0 \mathrm{eV}$, respectively, have been used to align the computed spectra with experiment. The top energy scale refers to the experimental results while the bottom energy scale refers to the theoretical calculations. These are displaced by the indicated energy shift. The hatched lines give positions of the calculated IPs.

(bonding)) character at low energy, with additional, stronger excitations to orbitals of $\sigma^{*} \mathrm{Si}-\mathrm{C}$ character in the middle and transitions to $\sigma^{*} \mathrm{Si}-\mathrm{O}$ and $\sigma^{*} \mathrm{Si}-\mathrm{C}$ (with $\pi^{*} \mathrm{Si}-\mathrm{O}$ character) orbitals on the high-energy side of the band. A schematic of the final orbital of the strongest $\mathrm{Si} 2 \mathrm{p} \rightarrow \sigma^{*} \mathrm{Si}-\mathrm{C}$ transition is shown in
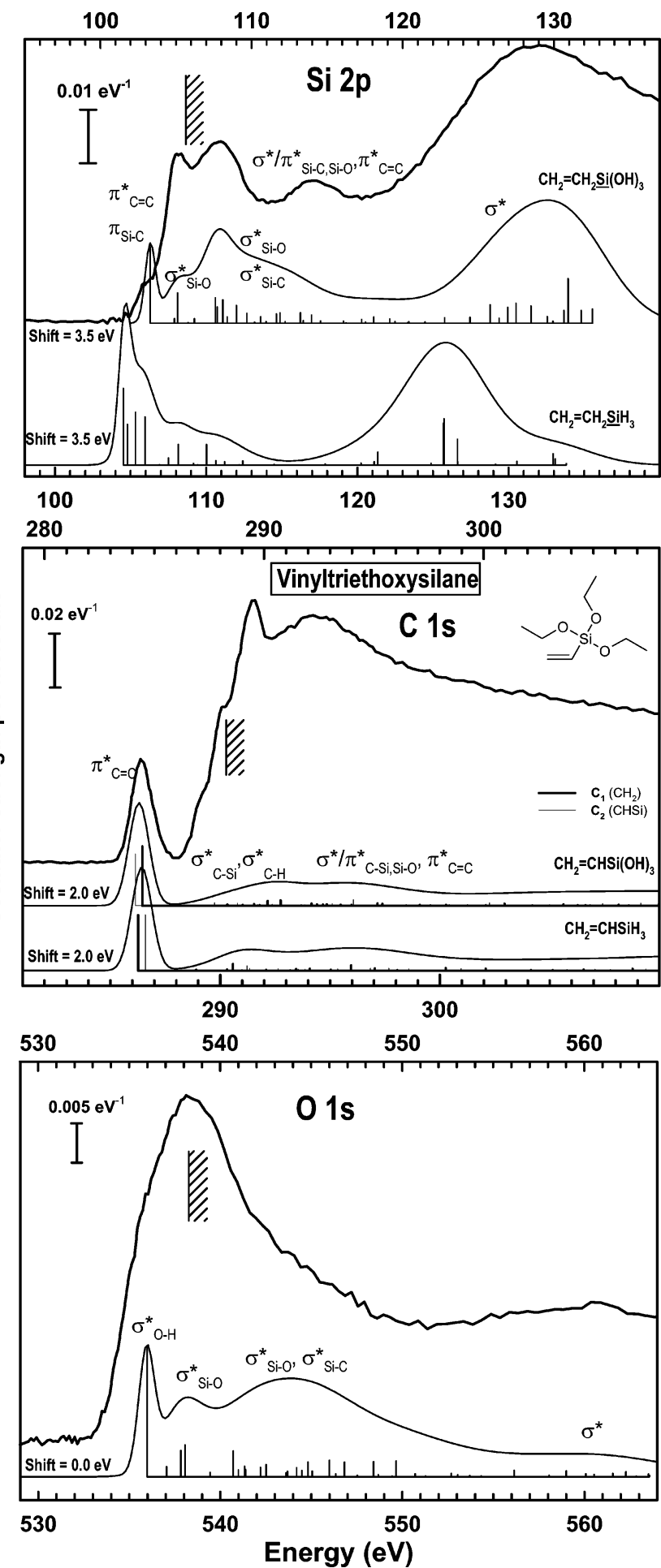

Figure 6. Simulated $\mathrm{Si} 2 \mathrm{p}$ and $\mathrm{C} 1 \mathrm{~s}$ 1s spectra of vinyltrihydroxysilane and vinylsilane and $\mathrm{O} 1 \mathrm{~s}$ spectrum of vinyltrihydroxysilane computed by GSCF3 ab initio methods, compared to the corresponding experimental spectra of vinyltriethoxysilane. Shifts of 3.5, 2.0, and $0.0 \mathrm{eV}$, respectively, have been used to align the computed spectra with experiment. The top energy scale refers to the experimental results while the bottom energy scale refers to the theoretical calculations. The hatched lines give positions of the calculated IPs.

Figure 8 . The large broad peak at $\sim 128 \mathrm{eV}$ arises from the overlap of transitions to many different $\sigma^{*}$ orbitals.

The $\mathrm{C} 1 \mathrm{~s}$ and $\mathrm{O} 1 \mathrm{~s}$ experimental spectra of trimethylethoxysilane are not simulated as well by the calculations. Only some transitions can be identified using the calculations, and relative spectral intensities differ from experiment. Note that since we 


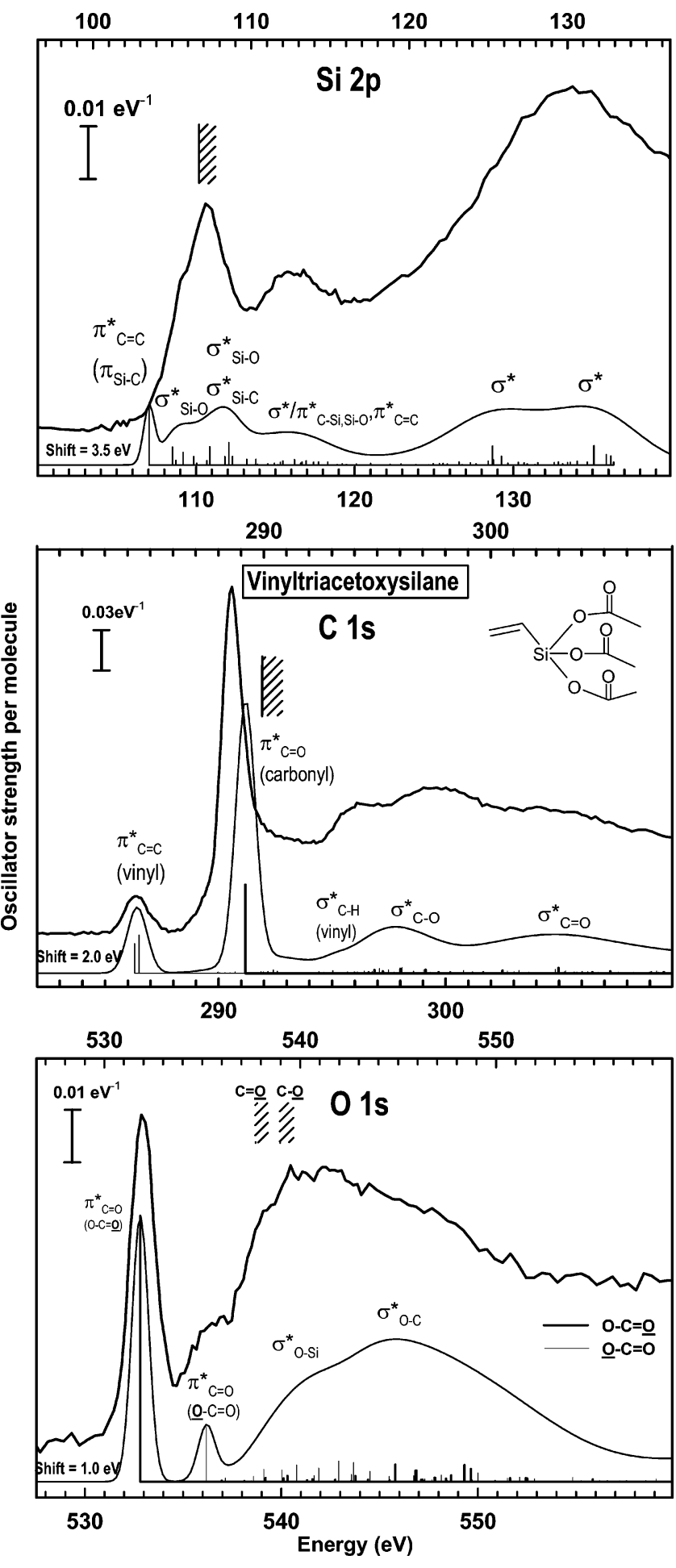

Figure 7. Simulated $\mathrm{Si} 2 \mathrm{p}, \mathrm{C} 1 \mathrm{~s}$, and $\mathrm{O} 1 \mathrm{~s}$ spectra of vinyltriformoxysilane computed by GSCF3 vinyltriacetoxysilane methods, compared to the corresponding experimental spectra of vinyltriacetoxysilane. Shifts of $3.5,2.0$, and $1.0 \mathrm{eV}$, respectively, have been used to align the computed spectra with experiment. The top energy scale refers to the experimental results while the bottom energy scale refers to the theoretical calculations. The hatched lines give positions of the calculated IPs.

are calculating the spectrum of the hydroxyl, rather than the ethoxy species, there is a large amount of $\mathrm{C} 1 \mathrm{~s}$ signal that is not accounted for, and significant changes in the $\mathrm{O} 1 \mathrm{~s}$ spectrum will occur due to the change from a local $\mathrm{Si}-\mathrm{O}-\mathrm{CR}$ environment to a $\mathrm{Si}-\mathrm{O}-\mathrm{H}$ environment. Nevertheless, the broad peaks at $\sim 290 \mathrm{eV}$ in the $\mathrm{C} 1 \mathrm{~s}$ spectrum and $\sim 537 \mathrm{eV}$ in the $\mathrm{O} 1 \mathrm{~s}$ spectrum are identified by the calculations as mainly $\mathrm{C} 1 \mathrm{~s} \rightarrow$ $\sigma^{*} \mathrm{Si-C}$ and $\mathrm{O} 1 \mathrm{~s} \rightarrow \sigma^{*} \mathrm{Si}-\mathrm{O}$, respectively (see Figure 8 for $\mathrm{MO}$ schematics). In the $\mathrm{C} 1 \mathrm{~s}$ spectrum, several of the calculated $\mathrm{C}$ $1 \mathrm{~s} \rightarrow \sigma^{*} \mathrm{Si}-\mathrm{C}$ bands in the main peak also show significant $\sigma^{*} \mathrm{C}-\mathrm{H}$ character. Higher-energy $\mathrm{C} 1 \mathrm{~s} \rightarrow \sigma^{*} \mathrm{Si}-\mathrm{C}$ bands show $\sigma^{*} \mathrm{C}-\mathrm{C}$ as well as $\sigma^{*} \mathrm{Si}-\mathrm{C}$ character. The peak at $\sim 287.5 \mathrm{eV}$ in the $\mathrm{C} 1 \mathrm{~s}$ experimental spectrum is not reproduced in the calculations and is therefore most likely the $\mathrm{C} 1 \mathrm{~s} \rightarrow 3 \mathrm{p}$ Rydberg transition. The strong peak at low energy in the computed $\mathrm{O} 1 \mathrm{~s}$ spectra is an $\mathrm{O} 1 \mathrm{~s} \rightarrow \sigma^{*}{ }_{\mathrm{O}-\mathrm{H}}$ transition. This band is not present in the experimental spectrum, simply because the model compound contains an $(\mathrm{O}-\mathrm{H})$ group that is not present in the molecule studied experimentally.

4.2. Vinyltrihydroxysilane. Figure 6 plots the $\mathrm{Si} 2 \mathrm{p}$ and $\mathrm{C}$ 1s spectra computed by GSCF3 for vinyltrihydroxysilane and vinylsilane and the $\mathrm{O} 1 \mathrm{~s}$ spectrum computed for vinyltrihydroxysilane. Vinylsilane is included to gain insight into the origin of transitions arising mainly from the vinyl grouping. The experimental spectra of vinyltriethoxysilane are included for comparison. Note that the energies and intensities in Figure 6 are on absolute scales for the full molecules, both the computed and experimental results (offsets are used for clarity). Table 5 summarizes the calculated transition energies, oscillator strengths, and orbital characters of selected low-energy states of vinyltrihydroxysilane. The low-energy shoulder at $\sim 103.6$ $\mathrm{eV}$ in the experimental $\mathrm{Si} 2 \mathrm{p}$ spectrum can be identified with the calculated $\mathrm{Si} 2 \mathrm{p} \rightarrow \pi^{*}{ }_{\mathrm{C}=\mathrm{C}}$ transition. This transition gains some intensity from the fact that this final orbital has some density on the $\mathrm{Si}$ due to having some $\mathrm{C}-\mathrm{Si} \pi$ bonding character (see Figure 8 for MO schematic). Similar transitions can be identified in the calculated spectrum for vinylsilane at slightly lower energy. The next two features in the Si $2 \mathrm{p}$ spectrum at 105.6 and $108.4 \mathrm{eV}$ correspond to transitions predicted by the GSCF3 calculations to have $\mathrm{Si} 2 \mathrm{p} \rightarrow \sigma^{*} \mathrm{Si}-\mathrm{O}$ and $\mathrm{Si} 2 \mathrm{p} \rightarrow$ $\sigma^{*} \mathrm{Si}-\mathrm{O}, \mathrm{Si}-\mathrm{C}$ character. As discussed above in section 3 , the presence of the low-energy structures in the computed $\mathrm{Si} 2 \mathrm{p}$ spectra supports our assignment of the additional sharp, lowenergy structure seen experimentally in the vinyl silicon species to $\mathrm{Si} 2 \mathrm{p}$ excitations to orbitals associated with the presence of the vinyl group. This indicates there is considerable delocalization of the $\pi^{*} \mathrm{C}=\mathrm{C}$ character onto the $\mathrm{Si}$ atom. The higherenergy peak at $\sim 114 \mathrm{eV}$ in the experimental spectrum is computed to be composed of transitions to final states involving the vinyl group $\pi^{*}{ }_{C}=\mathrm{C}$ system, the $\mathrm{Si}$ atom, and the $\mathrm{OH}$ groups. As such, these final orbitals have $\mathrm{Si}-\mathrm{O}, \mathrm{Si}-\mathrm{C}$, and $\mathrm{C}=\mathrm{C}$ antibonding character. They therefore appear at high energy in the calculated and experimental spectra. These transitions could best be described as $\mathrm{Si} 2 \mathrm{p} \rightarrow \sigma^{*} / \pi^{*} \mathrm{Si}-\mathrm{O}, \mathrm{Si}-\mathrm{C}, \pi^{*}{ }_{\mathrm{C}}=\mathrm{C}$ (Figure 8). As would be expected from this assignment, these transitions have an analogue in the vinyltriacetoxysilane $\mathrm{Si} 2 \mathrm{p}$ spectrum (see below) but not in the trimethylethoxysilane $\mathrm{Si} 2 \mathrm{p}$ spectrum or the vinylsilane theoretical spectrum.

The $\mathrm{C}$ 1s spectrum of vinyltriethoxysilane is dominated by the very intense $\mathrm{C} 1 \mathrm{~s}(\mathrm{C}=\mathrm{C}) \rightarrow \pi^{*}{ }_{\mathrm{C}}=\mathrm{C}$ peak at $\sim 284.4 \mathrm{eV}$. Transitions from the $\mathrm{C} 1 \mathrm{~s}$ orbitals in the $=\mathrm{CH}_{2}$ and $=\mathrm{CHSi}$ groupings occur at very similar energies such that the peaks overlap in the experimental spectrum. A plot of the final orbital of the $\mathrm{C} 1 \mathrm{~s}(\mathrm{C}=\mathrm{C}) \rightarrow \pi^{*} \mathrm{C}=\mathrm{C}$ transition is shown in Figure 8 . The calculated peaks in the $\sim 286-290 \mathrm{eV}$ spectral region have $\mathrm{C} 1 \mathrm{~s} \rightarrow \sigma^{*}{ }_{\mathrm{C}-\mathrm{Si}}$ and $\mathrm{C} 1 \mathrm{~s} \rightarrow \sigma^{*}{ }_{\mathrm{C}-\mathrm{H}}$ character. The strong peak at $\sim 289.5 \mathrm{eV}$ in the experimental spectrum, while not calculated to be particularly intense, may be due to a $\mathrm{C} 1 \mathrm{~s} \rightarrow \sigma^{*} \mathrm{C}-\mathrm{H}$ transition that is particularly localized on the $\mathrm{Si}-\mathrm{C}-\mathrm{H}$ grouping. The higher-energy broad feature centered at $\sim 292.5 \mathrm{eV}$ is 


\section{Trimethylhydroxysilane}

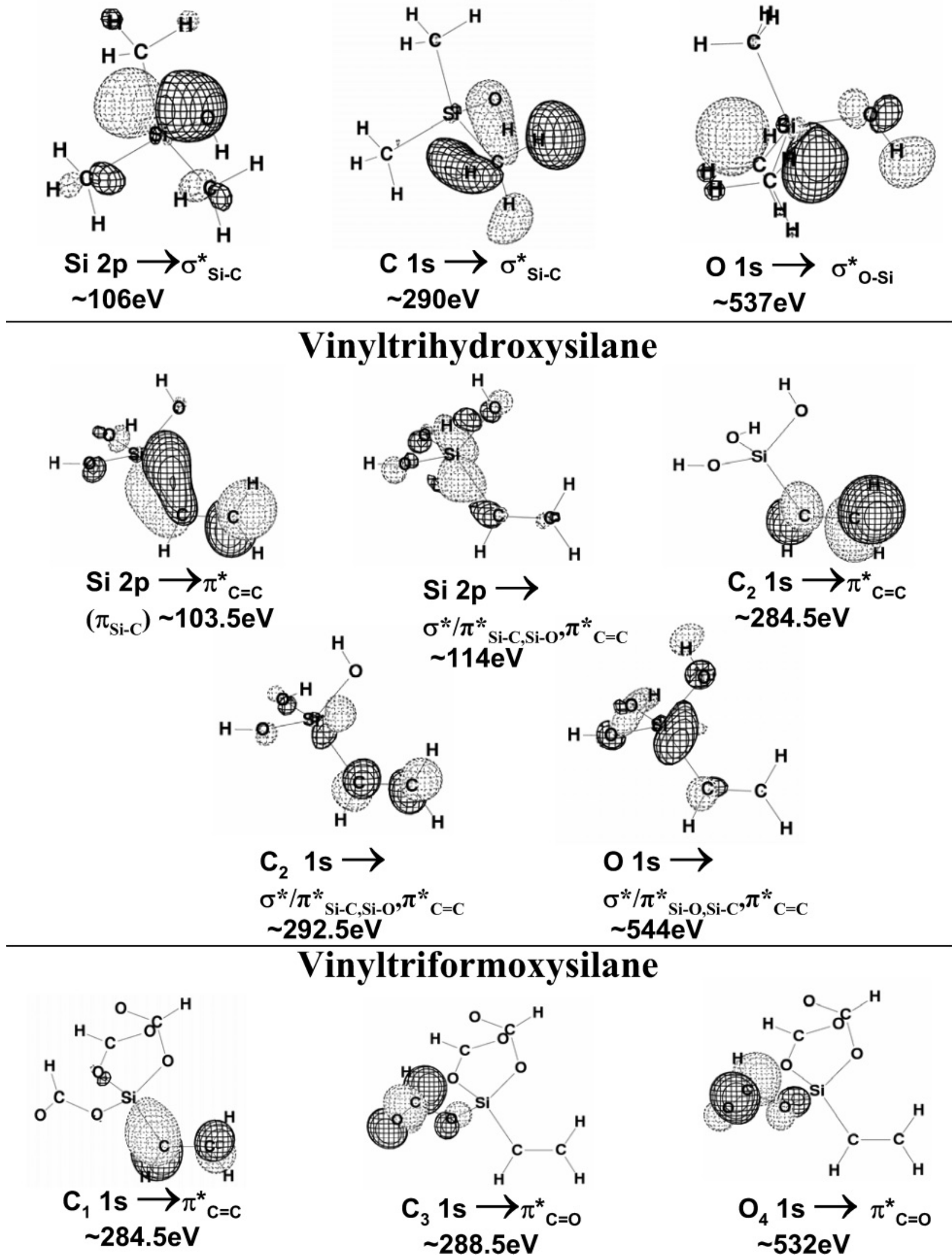

Figure 8. Plots of selected theoretically calculated molecular orbitals in core-excited states of trimethylhydroxysilane, vinyltrihydroxysilane, and vinyltriformoxysilane. In each case, the computed transition energy, the core-excitation site, and the dominant character of the upper orbital are indicated.

comprised at least partly of the C 1s counterpart of the highly antibonding Si 2p transition mentioned above, which has $\mathrm{C} 1 \mathrm{~s}$ $\rightarrow \sigma^{*} / \pi^{*} \mathrm{Si}-\mathrm{C}, \mathrm{Si}-\mathrm{O}, \pi^{*} \mathrm{C}=\mathrm{C}$ character (Figure 8). Note that the computed $\mathrm{C} 1 \mathrm{~s}$ spectrum in Figure 5 appears much weaker than the experimental spectrum due to the absence of the ethoxy carbon contributions in the calculation. 
TABLE 5: Energies and MO Character of Selected Inner-Shell-Excited States from GSCF3 Calculations of Trimethylhydroxysilane, Vinyltrihydroxysilane, and Vinyltriformoxysilane

\begin{tabular}{|c|c|c|c|c|}
\hline site & IP (calcd) & orbital character & $-\epsilon(\mathrm{eV})$ & $f\left(10^{-2}\right)$ \\
\hline \multirow[t]{3}{*}{$\mathrm{Si}$} & \multirow[t]{3}{*}{107.12} & $\begin{array}{l}\text { Trimethylhydroxysilane } \\
\sigma^{*}(\mathrm{Si}-\mathrm{C}), \pi(\mathrm{Si}-\mathrm{O})\end{array}$ & 0.08 & 1.26 \\
\hline & & $\sigma^{*}(\mathrm{Si}-\mathrm{C})$ & -1.73 & 1.90 \\
\hline & & $\sigma^{*}(\mathrm{O}-\mathrm{Si}-\mathrm{C})$ & -7.48 & 0.37 \\
\hline \multirow[t]{2}{*}{$\mathrm{C}$} & \multirow[t]{2}{*}{290.31} & $\sigma^{*}(\mathrm{C}-\mathrm{Si}), \sigma^{*}(\mathrm{C}-\mathrm{H})$ & -1.32 & 1.22 \\
\hline & & $\sigma^{*}(\mathrm{C}-\mathrm{Si}-\mathrm{O})$ & -6.69 & 0.41 \\
\hline \multirow[t]{3}{*}{$\mathrm{O}$} & \multirow[t]{3}{*}{537.64} & $\sigma^{*}(\mathrm{O}-\mathrm{H})$ & 2.02 & 0.60 \\
\hline & & $\sigma^{*}(\mathrm{Si}-\mathrm{O})$ & -1.75 & 0.75 \\
\hline & & $\sigma^{*}(\mathrm{O}-\mathrm{Si}-\mathrm{C})$ & -6.85 & 0.21 \\
\hline \multirow{3}{*}{$\mathrm{Si}$} & \multirow{3}{*}{108.80} & Vinyltrihydroxysilane & & \\
\hline & & $\pi^{*}(\mathrm{C}=\mathrm{C}), \pi(\mathrm{Si}-\mathrm{C})$ & 2.50 & 0.76 \\
\hline & & $\sigma / \pi^{*}(\mathrm{Si}-\mathrm{C}, \mathrm{Si}-\mathrm{O}), \pi^{*}(\mathrm{C}=\mathrm{C})$ & -7.44 & 0.52 \\
\hline \multirow[t]{2}{*}{$\mathrm{C}_{1}\left(\mathrm{CH}_{2}\right)$} & \multirow[t]{2}{*}{290.87} & $\pi^{*}(\mathrm{C}=\mathrm{C})$ & 4.41 & 2.90 \\
\hline & & $\sigma / \pi^{*}(\mathrm{C}-\mathrm{Si}, \mathrm{Si}-\mathrm{O}), \pi^{*}(\mathrm{C}=\mathrm{C})$ & -6.23 & 0.54 \\
\hline \multirow[t]{2}{*}{$\mathrm{C}_{2}(\mathrm{CHSi})$} & \multirow[t]{2}{*}{290.24} & $\pi^{*}(\mathrm{C}=\mathrm{C})$ & 4.11 & 2.53 \\
\hline & & $\sigma / \pi^{*}(\mathrm{C}-\mathrm{Si}, \mathrm{Si}-\mathrm{O}), \pi^{*}(\mathrm{C}=\mathrm{C})$ & -5.83 & 1.47 \\
\hline $\mathrm{O}$ & 538.22 & $\sigma / \pi^{*}(\mathrm{O}-\mathrm{Si}, \mathrm{Si}-\mathrm{C}), \pi^{*}(\mathrm{C}=\mathrm{C})$ & -6.79 & 0.11 \\
\hline \multirow{4}{*}{$\mathrm{Si}$} & \multirow{4}{*}{110.06} & Vinyltriformoxysilane & & \\
\hline & & $\pi^{*}(\mathrm{C}=\mathrm{C}), \pi(\mathrm{Si}-\mathrm{C})$ & 3.03 & $\begin{array}{l}0.88 \\
0.69\end{array}$ \\
\hline & & $\sigma^{*}(\mathrm{Si}-\mathrm{O})$ & 1.54 & $\begin{array}{l}0.69 \\
0.23\end{array}$ \\
\hline & & $\sigma / \pi^{*}(\mathrm{Si}-\mathrm{C}, \mathrm{Si}-\mathrm{O}), \pi^{*}(\mathrm{C}=\mathrm{C})$ & -7.66 & 0.23 \\
\hline \multirow[t]{2}{*}{$\mathrm{C}_{1}\left(\mathrm{CH}_{2}\right)$} & \multirow[t]{2}{*}{291.73} & $\pi^{*}(\mathrm{C}=\mathrm{C})$ & 5.23 & 3.04 \\
\hline & & $\pi^{*}(\mathrm{C}=\mathrm{O})$ & 0.94 & 0.02 \\
\hline \multirow[t]{2}{*}{$\mathrm{C}_{2}(\mathrm{CHSi})$} & \multirow[t]{2}{*}{291.09} & $\pi^{*}(\mathrm{C}=\mathrm{C})$ & 4.79 & 2.36 \\
\hline & & $\pi^{*}(\mathrm{C}=\mathrm{O})$ & 1.05 & 0.10 \\
\hline \multirow[t]{2}{*}{$\mathrm{C}_{3}(\mathrm{C}=\mathrm{O})$} & \multirow[t]{2}{*}{297.14} & $\pi^{*}(\mathrm{C}=\mathrm{O})$ & 5.97 & 6.77 \\
\hline & & $\pi^{*}(\mathrm{C}=\mathrm{C})$ & 2.11 & 0.21 \\
\hline \multirow{2}{*}{$\mathrm{C}_{4}(\mathrm{C}=\mathrm{O})$} & \multirow[t]{2}{*}{297.77} & $\pi^{*}(\mathrm{C}=\mathrm{O})$ & 6.60 & 7.06 \\
\hline & & $\pi^{*}(\mathrm{C}=\mathrm{C})$ & 1.79 & 0.08 \\
\hline \multirow[t]{2}{*}{$\mathrm{C}_{5}(\mathrm{C}=\mathrm{O})$} & \multirow[t]{2}{*}{297.67} & $\pi^{*}(\mathrm{C}=\mathrm{O})$ & 6.47 & 7.03 \\
\hline & & $\pi^{*}(\mathrm{C}=\mathrm{C})$ & 2.22 & 0.05 \\
\hline \multirow[t]{2}{*}{$\mathrm{O}(\mathrm{C}=\mathrm{O})$} & \multirow[t]{2}{*}{538.69} & $\pi^{*}(\mathrm{C}=\mathrm{O})$ & 5.87 & 1.78 \\
\hline & & $\pi^{*}(\mathrm{C}=\mathrm{C})$ & 1.72 & 0.02 \\
\hline \multirow[t]{2}{*}{$\mathrm{O}(\mathrm{C}-\mathrm{O})$} & \multirow[t]{2}{*}{539.94} & $\pi^{*}(\mathrm{C}=\mathrm{O})$ & 3.74 & 0.37 \\
\hline & & $\pi^{*}(\mathrm{C}=\mathrm{C})$ & 2.78 & 0.02 \\
\hline
\end{tabular}

${ }^{a}$ The predicted spectra shown in Figures $5-7$ were generated using Gaussian lines of area given by the computed oscillator strength $(f)$ and widths for the $\mathrm{C} 1 \mathrm{~s}$ and $\mathrm{O} 1 \mathrm{~s}$ spectra of $1.0 \mathrm{eV}(\epsilon \leftarrow 2 \mathrm{eV}), 2.5 \mathrm{eV}$ $(-2.0 \mathrm{eV}<\epsilon<2.0 \mathrm{eV}), 5.0 \mathrm{eV}(2.0 \mathrm{eV}<\epsilon<8.0 \mathrm{eV})$, and $8.0 \mathrm{eV}$ $(\epsilon>8.0 \mathrm{eV})$. For the $\mathrm{Si} 2 \mathrm{p}$ spectra, the widths used were $0.8 \mathrm{eV}(\epsilon \leftarrow$ $2 \mathrm{eV}), 2.0 \mathrm{eV}(-2.0 \mathrm{eV}<\epsilon<2.0 \mathrm{eV}), 4.0 \mathrm{eV}(2.0 \mathrm{eV}<\epsilon<8.0 \mathrm{eV})$, and $6.0 \mathrm{eV}(\epsilon>8.0 \mathrm{eV})$.

The experimental $\mathrm{O} 1 \mathrm{~s}$ spectrum of vinyltriethoxysilane is relatively featureless compared with the $\mathrm{Si} 2 \mathrm{p}$ or $\mathrm{C} 1$ s spectra. The main broad band centered at $\sim 538 \mathrm{eV}$ can be identified as being comprised of $\mathrm{O} 1 \mathrm{~s} \rightarrow \sigma^{*} \mathrm{O}-\mathrm{Si}$ transitions. At higher energies, the mainly $\sigma^{*} \mathrm{O}-\mathrm{Si}$ final orbitals contain progressively more $\sigma^{*} \mathrm{O}-\mathrm{O}$ (intergroup) and $\sigma^{*} \mathrm{Si}-\mathrm{C}$ character. The calculations again identify a transition at $\sim 544 \mathrm{eV}$ to a very antibonding delocalized $\sigma^{*} / \pi^{*} \mathrm{Si}-\mathrm{C}, \mathrm{Si}-\mathrm{O}, \pi^{*}{ }_{\mathrm{C}=\mathrm{C}}$ final orbital (Figure 8 ), which may contribute to the broadness of the main $\mathrm{O} 1 \mathrm{~s}$ band in this energy region. As in the case of trimethylhydroxysilane, the calculations for vinyltrihydroxysilane predict a strong peak at low transition energy in the $\mathrm{O} 1 \mathrm{~s}$ spectrum of $\mathrm{O} 1 \mathrm{~s} \rightarrow \sigma^{*} \mathrm{O}-\mathrm{H}$ character. This band is not observed in the experimental spectrum simply because the model compound contains $\mathrm{O}-\mathrm{H}$ bonds while vinyltriethoxysilane does not.

4.3. Vinyltriformoxysilane. Figure 7 plots the Si 2p, C 1s, and $\mathrm{O} 1 \mathrm{~s}$ spectra computed by GSCF3 for vinyltriformoxysilane compared with the corresponding experimental spectra of vinyltriacetoxysilane. The energies and intensities in Figure 7 are on absolute scales for the full molecule, for both the computed and experimental results (offsets are used for clarity). Table 5 summarizes the calculated transition energies, oscillator strengths, and orbital characters of selected low-energy states of vinyltriformoxysilane. Similar to the spectra for vinyltriethoxysilane and trimethylethoxysilane, the theoretically simulated spectra for vinyltriformoxysilane do not closely reproduce the vinyltriacetoxysilane spectra; however, the calculated transitions do correspond to observed features in the experimental spectra. The low-energy shoulder at $\sim 104.0 \mathrm{eV}$ in the Si $2 \mathrm{p}$ experimental spectrum can be identified with a calculated $\mathrm{Si}$ $2 \mathrm{p} \rightarrow \pi^{*}{ }_{\mathrm{C}=\mathrm{C}}$ transition that has $\pi_{\mathrm{Si}=\mathrm{C}}$ character (similar to the vinyltriethoxysilane $\mathrm{Si} 2 \mathrm{p}$ spectrum). The next-highest-energy calculated transitions are $\mathrm{Si} 2 \mathrm{p} \rightarrow \sigma^{*} \mathrm{Si}-\mathrm{O}$ in character, again as in vinyltriethoxysilane. The shoulder at $105.7 \mathrm{eV}$ in the experimental spectrum of vinyltriacetoxysilane is likely due to these transitions. At slightly higher energy, the $\mathrm{Si} 2 \mathrm{p} \rightarrow \sigma_{\mathrm{Si}}^{*} \mathrm{O}$, $\mathrm{Si}_{-\mathrm{C}}$ transitions are calculated to make up most of the intensity of the band centered at $\sim 107.3 \mathrm{eV}$ (although the calculations give slightly higher transition energies). The analogues of the highly antibonding final state transitions in the vinyltriethoxysilane spectra can be seen at $\sim 112.5 \mathrm{eV}$ in vinyltriacetoxysilane. In this case, it is not possible to isolate one calculated final state orbital to demonstrate the orbital character since the molecule and basis set used are too large to allow a very simple interpretation. Nevertheless, the final state orbital characters in this spectral energy region are $\sigma^{*} / \pi^{*} \mathrm{Si}-\mathrm{C}, \mathrm{Si}-\mathrm{O}, \pi^{*} \mathrm{C}=\mathrm{C} . \mathrm{C}=\mathrm{O}$, as might be expected by analogy with vinyltriethoxysilane.

The $\mathrm{C} 1 \mathrm{~s}$ spectrum of vinyltriacetoxysilane is dominated by $\mathrm{C} 1 \mathrm{~s}(\mathrm{C}=\mathrm{C}) \rightarrow \pi^{*}{ }_{\mathrm{C}=\mathrm{C}}$ and $\mathrm{C} 1 \mathrm{~s}(\mathrm{C}=\mathrm{O}) \rightarrow \pi^{*}{ }_{\mathrm{C}=\mathrm{O}}$ transitions (Figure 7), which are reproduced reasonably by theory, although the spacing of the $\pi^{*} \mathrm{C}=\mathrm{C}$ and $\pi^{*} \mathrm{C}=\mathrm{O}$ bands differs from experiment. The calculations indicate the low-energy shoulder on the main $\mathrm{C} 1 \mathrm{~s} \rightarrow \pi^{*} \mathrm{C}=\mathrm{O}$ peak at $288.6 \mathrm{eV}$ is a low-intensity "crossover" peak from $\mathrm{C} 1 \mathrm{~s}(\mathrm{C}=\mathrm{C}) \rightarrow \pi^{*}{ }_{\mathrm{C}=\mathrm{O}}$ transitions. A corresponding low-intensity $\mathrm{C} 1 \mathrm{~s}(\mathrm{C}=\mathrm{O}) \rightarrow \pi^{*} \mathrm{C}=\mathrm{C}$ "crossover" transition is calculated to occur at $\sim 293 \mathrm{eV}$, overlapping with $\mathrm{C} 1 \mathrm{~s}(\mathrm{C}=\mathrm{C}) \rightarrow \sigma^{*} \mathrm{C}-\mathrm{H}$ peaks. At higher energies, the shape of the experimental spectrum is not reproduced particularly well by the calculation due to absence of the contributions of the methyl moieties of the acetoxy groups, but the highest-intensity theoretical transitions, which are of $\sigma^{*}{ }_{\mathrm{C}=\mathrm{O}}$ and $\sigma^{*}{ }_{\mathrm{C}-\mathrm{O}}$ character, do match nicely with features attributed to $\mathrm{C} 1 \mathrm{~s}(\mathrm{C}=\mathrm{O}) \rightarrow \sigma^{*} \mathrm{C}=$ $\mathrm{O}$ and $\mathrm{C} 1 \mathrm{~s}(\mathrm{C}-\mathrm{O}) \rightarrow \sigma^{*}{ }_{\mathrm{C}-\mathrm{O}}$ in the empirical assignments.

In the $\mathrm{O} 1 \mathrm{~s}$ spectrum (Figure 7 ), the discrete peaks at $\sim 532$ and $\sim 535.4 \mathrm{eV}$ are identified by the calculations to be $\mathrm{O} 1 \mathrm{~s}-$ $(\mathrm{O}=\mathrm{C}) \rightarrow \pi^{*}{ }_{\mathrm{C}=\mathrm{O}}$ (see Figure 8 for MO schematic) and $\mathrm{O} 1 \mathrm{~s}-$ $(\mathrm{O}-\mathrm{C}) \rightarrow \pi^{*}{ }_{\mathrm{C}=\mathrm{O}}$ transitions. At higher energies, the shape of the experimental spectrum is again not well-reproduced by the calculations. The broad band from $\sim 537-552 \mathrm{eV}$ is calculated to be comprised of many overlapping transitions of mainly $\mathrm{O}$ $1 \mathrm{~s} \rightarrow \sigma^{*} \mathrm{O}-\mathrm{Si}$ and $\mathrm{O} 1 \mathrm{~s} \rightarrow \sigma^{*} \mathrm{O}-\mathrm{C}$ character.

\section{Application to Analysis of Adhesion Promoter Thin Films}

Adhesion promoters (AP) for use with silicon wafers often have the generalized chemical formula $\mathrm{G}-\mathrm{Si}(\mathrm{OR})_{3}$, where $\mathrm{R}$ can be methyl, ethyl, acetate, or other groups. The $\mathrm{R}$ group is hydrolyzed (usually in solution prior to application), and the resulting silanol group is understood to react with free hydroxyl groups on the oxidized silicon surface. The $G$ group consists of a moiety with favorable interaction with the polymer or organic phase. Adhesion promoters can be applied by spincasting, dipping, or vapor-dosing. As an example of our use of inner-shell spectroscopy to study adhesion promoters, Figure 9 compares X-PEEM and atomic force microscopy (AFM) results from as-made and annealed spin-coated adhesion promoter films 


\section{PEEM}

AFM

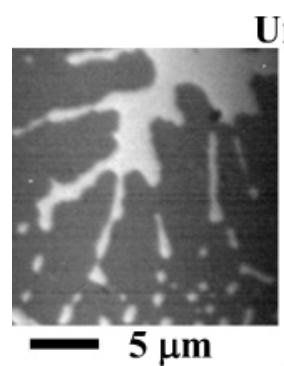

Unheated

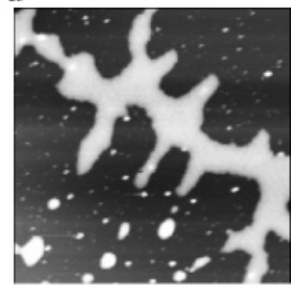

$100^{\circ} \mathrm{C}$
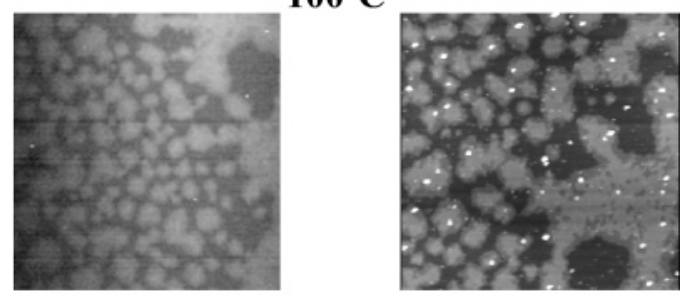

$180^{\circ} \mathrm{C}$
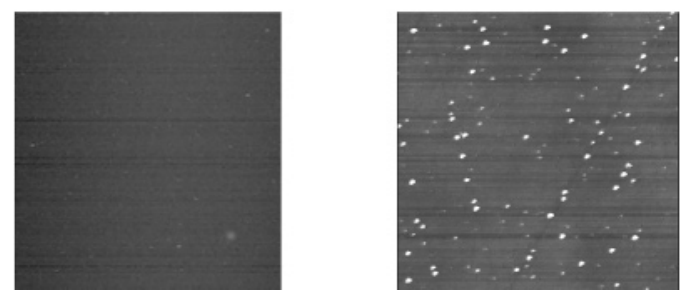

Figure 9. Comparison of PEEM and AFM images of a vinyltriacetoxysiloxane adhesion promoter (AP) on a silicon wafer. The small bright spots in the AFM images are artifacts. The change in the coverage with annealing initiated a concern that the AP did not fully cover (wet) the surface in the initial application.

on native oxide silicon. The contrast in the AFM image is purely topographic whereas the contrast in the X-PEEM images arises from a combination of topographic and spectroscopic contrast mechanisms. In X-PEEM, regions of low work function or higher curvature and thus higher field are brighter, giving rise to topographic contrast. In addition, if there is a difference in the chemical composition of the near surface region contributing to a given region imaged, then those regions for which there is a larger X-ray absorption will be brighter. The combination of AFM and X-PEEM visualization of adhesion promoter films provides a better understanding of the surface dispersion and how this changes with the typical curing that might be used prior to applying the polymer thin film. In addition to being able to examine coverage and morphology issues, changes in the inner-shell spectra with annealing give insights into the surface chemistry leading to adhesion.

For the film imaged in Figure 9, there was a partial hydrolysis in aqueous solution that resulted in some condensation polymerization of the AP, producing a moderate increase in its molecular weight. The partially polymerized AP solution was then spin-coated onto the Si substrates and heated to 100 or $180 \mathrm{C}^{\circ} .5$ The AFM image of the as-cast film in Figure 9 shows a structure that consists of ridges of material with occasional disconnected mounds of varying lateral size. AFM indicated the height of the ridges on the as-spun sample averaged about $11 \mathrm{~nm}$ and about $3 \mathrm{~nm}$ after heating the surface to $100 \mathrm{C}^{\circ}$. The surface heated to $180 \mathrm{C}^{\circ}$ was very smooth, lacking any obvious structure greater than $0.1 \mathrm{~nm}$. Ellipsometry indicated the thickness of the fully cured film was $2 \mathrm{~nm}$. The as-spun AFM image could be interpreted to indicate the adhesion promoter failed to wet the wafer surface. Chemical analysis of the smooth

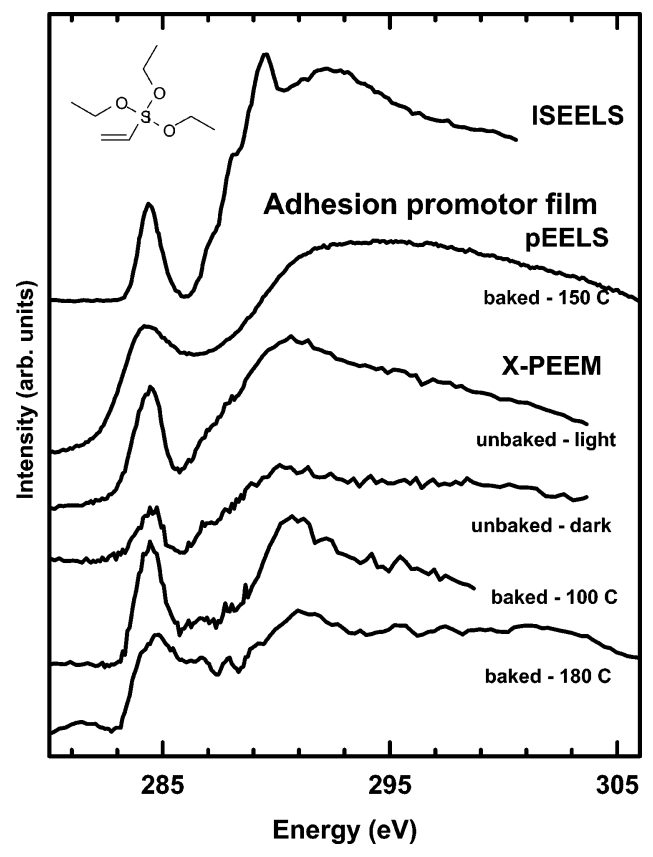

Figure 10. $\mathrm{C}$ 1s NEXAFS spectra measured in X-PEEM of the bright and dark areas of the unbaked adhesion promoter film shown in Figure 9, compared to the average spectra of a sample of the same batch of AP film annealed at 100 and $180 \mathrm{C}^{\circ}$. The $\mathrm{C} 1$ s spectrum of a spin-cast AP film annealed at $120 \mathrm{C}^{\circ}$, examined by TEM-EELS, and the gasphase spectrum of vinyltriethoxysilane are also plotted for comparison. All spectra were background-subtracted. Offsets are used for clarity.

regions was required to determine if this was the case. To interpret the surface chemistry changes seen in the X-PEEM and AFM images, image sequences and point spectra were recorded in the $\mathrm{C} 1 \mathrm{~s}$ and $\mathrm{O}$ 1s regions with X-PEEM. Figure 10 presents the spectra from the three surfaces in Figure 9. These results indicate the as-cast film has a continuous layer of adhesion promoter over the whole surface, even in the dark areas. The $\mathrm{C} 1 \mathrm{~s}$ signal in the light areas is approximately 4 times as intense as that in the dark areas. Note this may not reflect the relative thickness, since the sampling depth in X-PEEM is only a few nanometers (recently measured as $4 \pm 1 \mathrm{~nm}$ in polystyrene ${ }^{36}$ ). These results are consistent with a picture in which the features on the as-spun surface are formed by higher molecular weight "gels" that are produced by the molecular weight built in solution prior to spin-coating. Smaller molecular weight fractions (oligimers or monomer) still available in the solution are sufficient to cover the surface between the ridges. Of particular importance is the deduction from the spectroscopy (but not from imaging) that the AP fully wets the surface.

When the AP-covered $\mathrm{Si}$ wafer is heated to $100 \mathrm{C}^{\circ}$, the amount of organic material on the surface is considerably decreased in thickness, and the material in the ridges broadens, as indicated both by the morphological changes and also by an increase in the signal strength in the dark regions. After being heated to $180 \mathrm{C}^{\circ}$, the surface becomes uniformly coated and smooth. However, the C 1s spectrum recorded by X-PEEM clearly indicated a residual organic coating with a relatively strong signal at $284.4 \mathrm{eV}$. This indicates the vinyl groups that are required for adhesion to the polymer are retained with this annealing protocol. Although the energy resolution is considerably worse, the TEM-EELS spectrum also nicely shows the presence of the vinyl groups in a cured film. The stronger and broader signal in the C 1s continuum above $293 \mathrm{eV}$ may be associated with plural scattering. For reference, the ISEELS C 1s spectrum of vinyltriethoxysilane is also included in Figure 

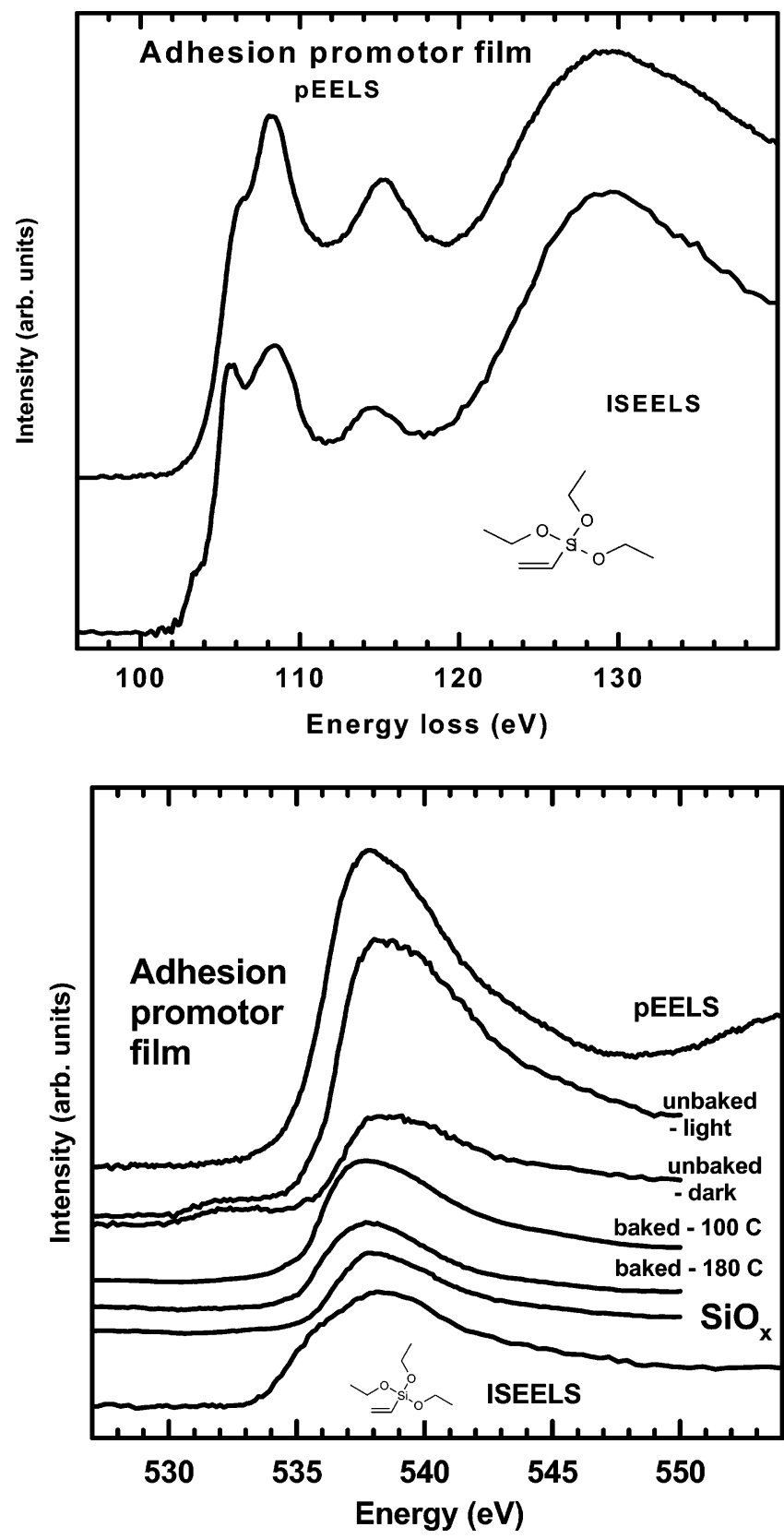

Figure 11. (Upper panel) Si $2 p$ spectrum of a spin-cast AP film annealed at $120 \mathrm{C}^{\circ}$, recorded by TEM-EELS, compared to the gasphase spectrum of vinyltriethoxysilane. (Lower panel) O1s spectra of the bright and dark areas of the unbaked AP film shown in Figure 8, compared to average spectra of the AP film annealed at 100 and 180 $\mathrm{C}^{\circ}$. The spectrum of a clean, native oxide silicon wafer is also plotted for comparison. The $\mathrm{O} 1 \mathrm{~s}$ spectrum of a different film annealed at 120 $\mathrm{C}^{\circ}$, examined by TEM-EELS, and the gas-phase spectrum of vinyltriethoxysilane are also plotted for comparison. All spectra were background-subtracted. Offsets are used for clarity.

10. This spectrum agrees well with the AP spectra, aside from the shoulders and peak at $289.5 \mathrm{eV}$ in the gas spectrum, which correspond to states with a large Rydberg character, which are quenched in the condensed state.

Figure 11 presents the Si 2p pEELS (upper) and O 1s pEELS and X-PEEM spectra (lower) of model AP films. The $\mathrm{O} 1 \mathrm{~s}$ $\mathrm{X}$-PEEM results correspond to the three samples shown in Figure 9 while the pEELS data is from a separate preparation of the AP on a carbon support. All of the O 1s spectra look superficially like that of native oxide silicon $\left(\mathrm{SiO}_{x}\right)$. However, close examination of the $\mathrm{O} 1 \mathrm{~s}$ signal of the as-cast film indicates
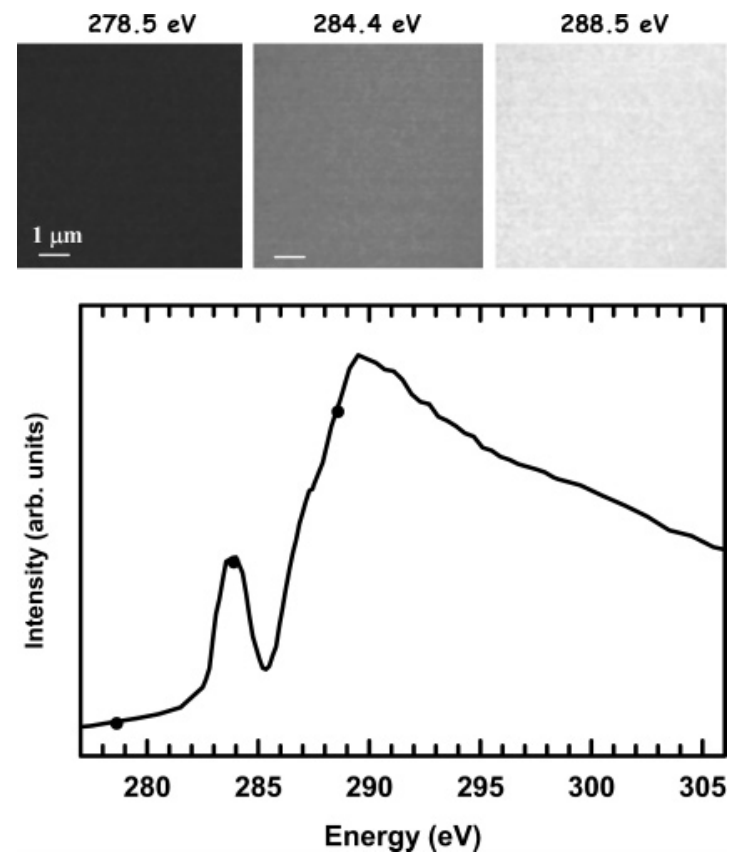

Figure 12. (Upper panel) Images recorded at 278.5, 284.4, and 288.5 $\mathrm{eV}$ of an optimized vinyltriacetoxysiloxane adhesion promoter film baked at $100 \mathrm{C}^{\circ}$. The gray scale of the three images is identical (black $=100$, white $=350)($ Lower panel) $\mathrm{C} 1 \mathrm{~s}$ spectrum of this film.

that the large broad peak peaking around $538 \mathrm{eV}$ is shifted to higher energy relative to $\mathrm{SiO}_{x}$ and there is additional signal at $532 \mathrm{eV}$. The latter appears to correspond to $\mathrm{O} 1 \mathrm{~s} \rightarrow \pi^{*} \mathrm{C}=\mathrm{O}$ transitions in the acetoxy group or acetic acid from hydrolysis that was retained in the as-spun film. After being heated, the $\mathrm{O}$ 1s spectrum of the film becomes essentially indistinguishable from that of native oxide silicon, suggesting that the environment of the $\mathrm{O}$ atoms is rather similar to that of $\mathrm{O}$ in $\mathrm{SiO}_{x}$. The $\mathrm{O} 1 \mathrm{~s}$ pEEL spectrum of the annealed AP does not show the $532 \mathrm{eV}$ signal, consistent with the X-PEEM result for baked AP films. The $\mathrm{Si} 2 \mathrm{p}$ spectrum recorded by $\mathrm{pEELS}$ is in excellent agreement with the $\mathrm{Si} 2 \mathrm{p}$ spectrum of vinyltriethoxysilane and distinctly different from the $\mathrm{Si} 2 \mathrm{p}$ spectra of the other two molecules studied in the gas phase. In particular, the peaks at $106.5,108.4$, and $114 \mathrm{eV}$ are all very prominent in the pEELS spectrum. The observation of the $114 \mathrm{eV}$ feature in the pEELS spectrum, attributed to $\operatorname{Si} 2 \mathrm{p} \rightarrow \pi^{*}$ vinyl transitions, and the 284.4 $\mathrm{eV}$ peak in the X-PEEM spectra, attributed to $\mathrm{C} 1 \mathrm{~s} \rightarrow \pi^{*}$ vinyl transitions, clearly shows that the vinyl groups are retained, even after the most vigorous thermal annealing used.

Figure 12 presents X-PEEM images recorded at 278.5, 284.4, and $288.5 \mathrm{eV}$ from an adhesion promoter film spin-coated on a silicon wafer, using optimized formulation and spin-coating parameters, subsequently baked at $100 \mathrm{C}^{\circ}$. The X-PEEM images readily confirm the process produces a film that is extremely uniform both morphologically and chemically. The presence of the vinyl groups that are key to adhesion promotion is confirmed by the $\mathrm{C} 1 \mathrm{~s}$ NEXAFS spectrum from this film.

\section{Summary}

The C 1s, Si 2p, and O 1s inner-shell excitation spectra of gaseous vinyltriethoxysilane, trimethylethoxysilane, and vinyltriacetoxysilane have been recorded by ISEELS, presented as absolute oscillator strengths, and analyzed according to empirical principles and in comparison with detailed ab initio calculations of related species. The $\mathrm{C} 1 \mathrm{~s}, \mathrm{O} 1 \mathrm{~s}$, and $\mathrm{Si} 2 \mathrm{p}$ absorption edges show characteristic features that can be useful fingerprints for 
understanding changes in the surface chemistry of adhesion promoters of similar chemical structure. Molecular orbital calculations provided additional details on the influence of bonding on spectral contributions.

The surface chemistry of adhesion promoters has been probed and visualized using X-PEEM and AFM. These results show that although initial preparations of the AP appear heterogeneous, they do fully wet the surface of the silicon wafer and they become chemically and morphologically homogeneous (as visualized with these methods) upon curing at elevated temperature. The chemical sensitivity of XPEEM considerably extended the strictly morphological AFM results. This was critical to understand that the surface chemistry was in fact uniform despite a heterogeneous topography. The combined XPEEM, pEELS, and AFM measurements were able to show that, with annealing, the process creates the conditions needed for spatially uniform bonding of the AP to the overlying polymer. Surface chemistry changes can be detected in terms of modifications to inner-shell excitation spectra sampled by XPEEM. The model spectra obtained by ISEELS are very useful in providing fingerprints for specific bonding motifs and in understanding the nature of the electronic transitions that occur in the spectra of the adhesion promoter films. Through this type of work, we can decipher the chemical nature of thin films and characterize the chemical changes occurring with annealing.

Acknowledgment. Research supported by NSERC (Canada), the Canada Research Chair program, and The Dow Chemical Company. D.T. thanks the Department of Chemistry for a summer research fellowship. Esta Halliday is acknowledged for assistance with early measurements. The authors also acknowledge the assistance of Frithjof Nolting, Andrew Doran, Andreas Scholl, and Simone Anders in acquisition of X-PEEM data at the ALS. The authors additionally thank colleagues in Advanced Electronic Materials and Analytical at Dow, especially Jay Im, for useful discussions and Diane Price for sample preparation and ellipsometric measurements. The ALS is supported by the Director, Office of Energy Research, Office of Basic Energy Sciences, Materials Sciences Division of the U. S. Department of Energy, under Contract No. DE-AC03-76SF00098.

\section{References and Notes}

(1) Plueddemann, E. Silane Coupling Agents; Plenum Press: New York, 1982; pp 1-2.

(2) Opila, R. L.; Legrange, J. D.; Markham, J. L.; Heyer, G.; Schroeder, C. M. J. Adhes. Sci. Technol. 1997, 11, 1-10.

(3) Grunze, M.; Schertel, A.; Uhrig, R.; Welle, A.; Woell, C.; Strunskus, T. J. Adhes. 1996, 58, 43.

(4) Seeboth, A.; Hettrich, W. J. Adhes. Sci. Technol. 1997, 11, 495.

(5) Im, J.; Shaffer, E.; Stokich, T.; Strandjord, A.; Hetzner, J.; Curphy, J.; Karas, C.; Meyers, G.; Hawn, D.; Chakrabarti, A.; Froelicher, S. On the Mechanical Reliability of Photo-BCB-Based Thin Film Dielectric Polymer for Electronic Packaging Applications. In Workshop on Mechanical Reliability of Polymeric Materials and Plastic Packages of IC Devices; ASME: New York, 1998; Vol. 25, p 191.

(6) Hitchcock, A. P.; Tyliszczak, T.; Urquhart, S. G.; Ade, H.; Murti, K.; Gerroir, P.; Rightor, E. G.; Lidy, W.; Dineen, M. T.; Mitchell, G. E.;
Steele, W. S.; Meigs, G.; Warwick, T. Soft X-ray Spectromicroscopy Studies of Industrial Polymers, 1998 ALS Compendium; Lawrence Berkeley National Laboratory: Berkeley, CA, 1999 (http://alspubs.lbl.gov/compendium/).

(7) Stöhr, J. NEXAFS Spectroscopy; Springer Tracts in Surface Science 25; Springer-Verlag: New York, 1992.

(8) Urquhart, S. G.; Hitchcock, A. P.; Leapman, R. D.; Priester, R. D.; Rightor, E. G. J. Polym. Sci., Part B: Polym. Phys. 1995, 33, 1593. (9) Urquhart, S. G.; Hitchcock, A. P.; Priester, R. D.; Rightor, E. G. J. Polym. Sci., Part B: Polym. Phys. 1995, 33, 1603.

(10) Urquhart, S. G.; Smith, A. P.; Ade, H. W.; Hitchcock, A. P.; Rightor, E. G.; Lidy, W. J. Phys. Chem. B 1999, 103, 4603.

(11) Urquhart, S. G.; Hitchcock, A. P.; Smith, A. P.; Ade, H.; Lidy, W.; Rightor, E. G.; Mitchell, G. E. J. Electron Spectrosc. Relat. Phenom. 1999, 100, 119.

(12) Rightor, E. G.; Urquhart, S. G.; Hitchcock, A. P.; Ade, H.; Smith, A. P.; Mitchell, G. E.; Priester, R. D.; Aneja, A.; Appel, G.; Wilkes, G.; Lidy, W. E. Macromolecules 2002, 35, 5873.

(13) Lawrence, J. R.; Swerhone, G. D. W.; Leppard, G. G.; Araki, T.; Zhang, X.; West, M. M.; Hitchcock, A. P. Appl. Environ. Microbiol. 2003 69, 5543.

(14) Urquhart, S. G.; Xiong, J. Z.; Wen, A. T.; Sham, T. K.; Baines, K. M. de Souza G. G. B.; Hitchcock, A. P. Chem. Phys. 1994, 189, 757.

(15) Urquhart, S. G.; Turci, C. C.; Tyliszczak, T.; Brook, M. A.; Hitchcock, A. P. Organometallics 1997, 16, 2080.

(16) Urquhart, S. G.; Hitchcock, A. P.; Lehmann, J. F.; Denk, M. K. Organometallics 1998, 17, 2352.

(17) Lehmann, J. F.; Urquhart, S. G.; Ennis, L.; Hitchcock, A. P.; Hatano, K.; Gupta, S.; Denk, M. K. Organometallics 1999, 18, 1862.

(18) Kosugi, N. Theor. Chim. Acta 1987, 72, 149.

(19) Kosugi, N.; Kuroda, H. Chem. Phys. Lett. 1980, 74, 490.

(20) Hitchcock, A. P. Phys. Scr. 1990, T31, 159.

(21) Hitchcock, A. P. J. Electron Spectrosc. Relat. Phenom. 2000, 112 ,

(22) Brion, C. E.; Daviel, S.; Sodhi, R. N. S.; Hitchcock, A. P. AIP Conf. Proc. 1982, 94, 429.

(23) Sodhi, R. N. S.; Brion, C. E. J. Electron Spectrosc. Relat. Phenom. 1984, 34, 363.

(24) Hitchcock, A. P.; Ishii, I. J. Electron Spectrosc. Relat. Phenom. 1987, 42,11 .

(25) Hitchcock, A. P.; Mancini, D. C. J. Electron Spectrosc. Relat. Phenom. 1994, 67, 1 .

(26) Anders, S.; Padmore, H. A.; Duarte, R. M.; Renner, T.; Stammler, T.; Scholl, A.; Scheinfein, M. R.; Stöhr, J.; Séve, L.; Sinkovic, B. Rev. Sci. Instrum. 1999, 7, 3973.

(27) Morin, C.; Ikeura-Sekiguchi, H.; Tyliszczak, T.; Cornelius, R.; Brash, J. L.; Hitchcock, A. P.; Scholl, A.; Nolting, F.; Appel, G.; Winesett, A. D.; Kaznatcheev, K.; Ade, H. J. Electron Spectrosc. Relat. Phenom. 2001, 121, 203.

(28) Jacobsen, C.; Wirick, S.; Flynn, G.; Zimba, C. J. Microsc. 2000, 197, 173.

(29) Henke, B. L.; Gullikson, E. M.; Davis, J. C. At. Data Nucl. Data Tables 1993 54, 181.

(30) aXis2000 is a freeware program written in interactive data language (IDL) and available from http://unicorn.mcmaster.ca/aXis2000.html

(31) Huzinaga, S.; Andzelm, J.; Klobokowski, M.; Radzio-Andzelm, E.; Sasaki, Y.; Tatewaki, H. Gaussian Basis Sets for Molecular Calculations; Elsevier: Amsterdam, 1984.

(32) Goddard, W. J.; Hunt, W. A. Chem. Phys. Lett. 1969, 3, 414.

(33) Gordon, M.; Cooper, G.; Araki, T.; Morin, C.; Turci, C. C.; Kaznatcheev, K.; Hitchcock, A. P. J. Phys. Chem A 2003, 107, 8512.

(34) Ishii, I.; Hitchcock, A. P. J. Electron Spectrosc. Relat. Phenom. 1987, 46,55

(35) Hitchcock, A. P.; Urquhart, S. G.; Rightor, E. G. J. Phys. Chem. A 1992, 96, 8736

(36) Morin, C.; Hitchcock, A. P.; Li, L.; Zhang, X.; Araki, T.; Scholl, A.; Doran, A., to be submitted for publication. 